\title{
Seasonal Timing for Estimating Carbon Mitigation in Revegetation of Abandoned Agricultural Land with High Spatial Resolution Remote Sensing
}

\author{
Ning Liu ${ }^{1,2, *}$, Richard J. Harper ${ }^{1,2}$, Rebecca N. Handcock ${ }^{1,3}$, Bradley Evans ${ }^{4}$, \\ Stanley J. Sochacki ${ }^{1}$, Bernard Dell ${ }^{1,2}$, Lewis L. Walden ${ }^{1}$ and Shirong Liu ${ }^{2, *}$ \\ 1 School of Veterinary and Life Sciences, Murdoch University, South Street, Murdoch, WA 6150, Australia; \\ R.Harper@murdoch.edu.au (R.J.H.); rebecca.handcock@ecu.edu.au (R.N.H.); \\ s.sochacki@murdoch.edu.au (S.J.S.); b.dell@murdoch.edu.au (B.D.); L.Walden@murdoch.edu.au (L.L.W.) \\ 2 Key Laboratory of Forest Ecology and Environment of State Forestry Administration, Institute of Forest \\ Ecology, Environment and Protection, Chinese Academy of Forestry, Beijing 10091, China \\ 3 Edith Cowan University, Joondalup, WA 6027, Australia \\ 4 School of Life and Environmental Sciences, The University of Sydney, Sydney, NSW 2006, Australia; \\ bradley.evans@sydney.edu.au \\ * Correspondence: ln1267@gmail.com or N.Liu@murdoch.edu.au (N.L.); Liusr@caf.ac.cn (S.L.); \\ Tel.: +61-8-9360-2191 (N.L.); +86-10-6288-9311 (S.L.)
}

Academic Editors: Lalit Kumar, Onisimo Mutanga and Randolph H. Wynne Received: 7 March 2017; Accepted: 24 May 2017; Published: 1 June 2017

\begin{abstract}
Dryland salinity is a major land management issue globally, and results in the abandonment of farmland. Revegetation with halophytic shrub species such as Atriplex nummularia for carbon mitigation may be a viable option but to generate carbon credits ongoing monitoring and verification is required. This study investigated the utility of high-resolution airborne images (Digital Multi Spectral Imagery (DMSI)) obtained in two seasons to estimate carbon stocks at the plant- and stand-scale. Pixel-scale vegetation indices, sub-pixel fractional green vegetation cover for individual plants, and estimates of the fractional coverage of the grazing plants within entire plots, were extracted from the high-resolution images. Carbon stocks were correlated with both canopy coverage $\left(R^{2}: 0.76-0.89\right)$ and spectral-based vegetation indices $\left(R^{2}: 0.77-0.89\right)$ with or without the use of the near-infrared spectral band. Indices derived from the dry season image showed a stronger correlation with field measurements of carbon than those derived from the green season image. These results show that in semi-arid environments it is better to estimate saltbush biomass with remote sensing data in the dry season to exclude the effect of pasture, even without the refinement provided by a vegetation classification. The approach of using canopy cover to refine estimates of carbon yield has broader application in shrublands and woodlands.
\end{abstract}

Keywords: aboveground biomass; Atriplex nummularia; carbon mitigation; carbon inventory; forage crops; remote sensing; vegetation index

\section{Introduction}

Global climate change is resulting from an imbalance in global greenhouse gas emissions [1]. A major strategy to mitigate carbon dioxide emissions is to sequester or remove carbon from the atmosphere through changing land use and increasing storage in plant biomass or soils [2,3]. Indeed, $83 \%$ of the mitigation targets or Intended Nationally Determined Contributions (INDCs) published following the 2015 Paris Climate Change Conference included the land sector [4]. However, carbon mitigation activities on farmland can displace food production [5] or affect water supplies [6]. 
Alternative mitigation approaches have been advocated, such as using low value or otherwise abandoned farmland to avoid competitive effects of vegetation [7].

In 2002, about 20,000 farms and 2 million hectares of agricultural land showed actual signs of salinity [8], and up to $170,000 \mathrm{~km}^{2}$ of land in Australia is predicted to be affected from salinity by 2050 [9] and up to 4 million $\mathrm{km}^{2}$ globally [10]. One option for salt-affected land is revegetation with salt-tolerant grazing plants such as Atriplex spp. [7]. Revegetation is a specific category of mitigation activity within the United Nations Framework Convention on Climate Change and is defined as the establishment of vegetation that does not meet the definitions of afforestation or reforestation. In Australia, this is defined as plants that do not exceed $2 \mathrm{~m}$ in height. Walden et al. [11] found consistent amounts of aboveground carbon stock $\left(0.2-0.6 \mathrm{t} \mathrm{C} \cdot \mathrm{ha}^{-1} \cdot\right.$ year $\left.^{-1}\right)$ by A. nummularia at six sites across southern Australia, with potential total sequestration of 1.1-3.6 Mt C.year ${ }^{-1}$, and studies (e.g., Harper et al. [2] and Harper et al. [12]) have described its usefulness as a grazing shrub in animal based farming systems.

To participate in carbon trading schemes, such as the Clean Development Mechanism or the Australian Carbon Farming Initiative [13], it is essential to measure and report amounts of carbon stocks. Ground-based field measurements of biomass are expensive. This study therefore evaluates the suitability of less expensive remote sensing approaches to estimate carbon stocks following farmland revegetation, with a focus on areas where there are low rates of sequestration. The calibration of remote sensing data with in situ measurements of biomass has the potential to be a cost effective means of reporting carbon stocks across landscapes, as well as being a timely source of data originating from direct observation of actual carbon stocks rather than being solely modelled values.

Analysis of high-resolution remotely sensed images can be at the scale of individual pixels (i.e., pixel-based) [14] or use approaches to extract multi-pixel features from the image (i.e., feature extraction, fractional coverage) [15], including the ability to use individual canopy crowns e.g. Bunting and Lucas [16] where the images are of sufficiently fine spatial resolution. Sochacki et al. [7] and Walden et al. [11] both found that aboveground biomass of $A$. nummularia followed a strong linear trend $\left(\mathrm{R}^{2}=0.81\right)$ in relation to a crown volume index $(\mathrm{CVI})$, calculated from crown width, length, and height. Walden et al. [11] also found that canopy diameter measurements were only slightly less predictive $\left(R^{2}=0.68\right)$ compared to $C V I$, and could be used to estimate aboveground biomass (AGB). The allometric relationship between biomass measurements and carbon estimates has been established [11] and these relationships could therefore be used as a basis for estimating carbon stocks in situations where individual crowns can be delineated from remote sensing images.

Although the use of pixel-based vegetation indices as proxies for estimating vegetation biomass is well established $[17,18]$, including examples such as the normalized difference vegetation index (NDVI), enhanced vegetation index (EVI) [19], and the ratio vegetation index (RVI) on forests [20], grass [21] and woodland [22,23], these techniques have been infrequently used to estimate carbon stocks in shrublands. However, the broader use of remote sensing for calibrating vegetation indices to biomass (e.g., Asner [24]) shows that the relationship between vegetation indices and biomass can differ between species, season, and the scale of the vegetation and pixels.

Estimates of canopy coverage derived from remote sensing images have also been applied as a proxy for calculating individual tree and stand biomass [25,26]. For example, Sousa et al. [27] found that the tree canopy horizontal projection derived from QuickBird satellite images produced highly accurate estimates of AGB of Quercus rotundifolia at both individual and plot scales. All of these approaches require remotely sensed images of sufficiently high spatial resolution to resolve the individual plants or stands being monitored.

In this study, we use high-resolution aerial images to explore characteristics of monitoring salt-tolerant grazing plants for carbon stocks in a Mediterranean environment. We derive estimates of canopy coverage from high spatial resolution airborne Digital Multi Spectral Imagery (DMSI) at two times of the year, and determine the utility of these images for estimating aboveground biomass and carbon stocks at both the plant- and stand-scale. Three remote sensing approaches were 
used: pixel-scale vegetation indices, extraction of the stand crowns from the high-resolution images, and estimation of the fractional coverage of the grazing plants within entire stands (Figure 1).

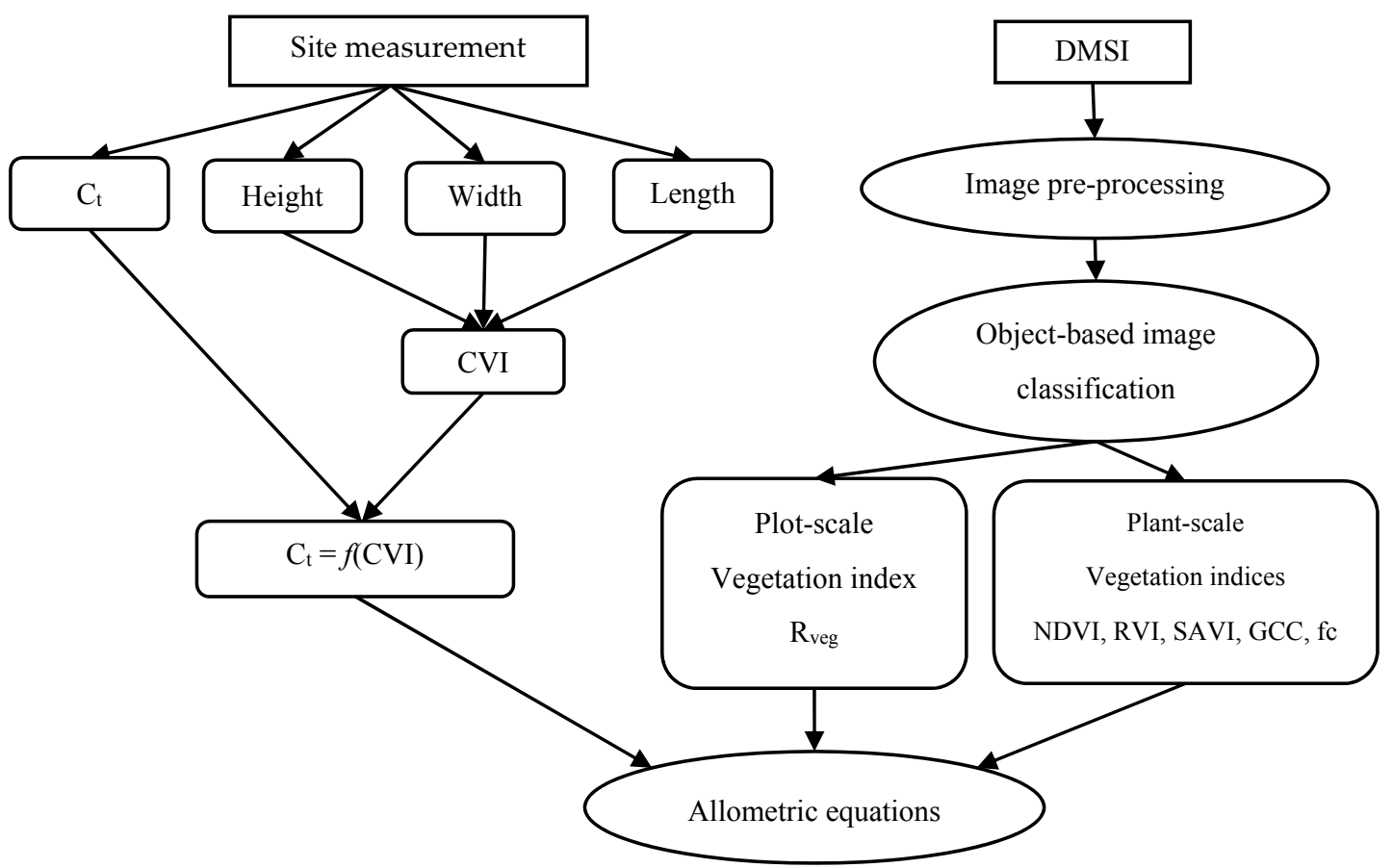

Figure 1. Flow diagram of the methodology followed in this study (where $C_{t}$ is the carbon stocks (t C.ha ${ }^{-1}$ ), DMSI is the Digital Multi Spectral Imagery, and CVI is the crown volume index). For definitions of vegetation indices, see Table 1.

Our specific objective was to determine if it is feasible to develop remote sensing models that can be used economically and efficiently to estimate carbon stocks at scales suitable for project level carbon accounting, and to determine the most suitable timing (e.g., wet season or dry season) for image acquisition for this purpose.

\section{Materials and Methods}

\subsection{Experimental Sites}

The study site $\left(32^{\circ} 43^{\prime} 34.33^{\prime \prime} \mathrm{S}, 117^{\circ} 39^{\prime} 55.27^{\prime \prime} \mathrm{E}\right)$ was located near Wickepin, Western Australia, and was established to investigate carbon stocks following revegetation of abandoned salinized farmland $[7,28]$. The region has a semi-arid Mediterranean climate, with a seasonal drought from November to April, and a mean annual rainfall of $357 \mathrm{~mm} \cdot$ year $^{-1}$ (2000-2011, Wickepin weather station No. 010654 from the Australian Bureau of Meteorology) and a mean annual pan evaporation of $1789 \mathrm{~mm} \cdot$ year $^{-1}$.

Atriplex nummularia was planted adjacent to a salt scald in 2001, at densities of 0,500 and 2000 plants ha ${ }^{-1}$, each with three replicates, in a randomized complete block design, consisting of two blocks (Figure 2). Details of seedling production and planting have been described previously [7]. At the time of field measurement in December 2011 (dry season), the low- and high-density stands had average heights of 2.17 and $1.68 \mathrm{~m}$, and average canopy diameters of 2.66 and $1.52 \mathrm{~m}$, respectively.

Both the control plots $\left(0\right.$ plants ha $\left.{ }^{-1}\right)$ and the areas between the A. nummularia plants were comprised of an array of annual volunteer pasture plants including capeweed (Arctotheca calendula), geranium (Erodium sp.), and various grasses (e.g., Hordeum glaucum, Lolium rigidum). As a consequence of the Mediterranean environment, the annual pasture plants are only alive in the period April-October, whereas the A. nummularia plants bear foliage year-round. 


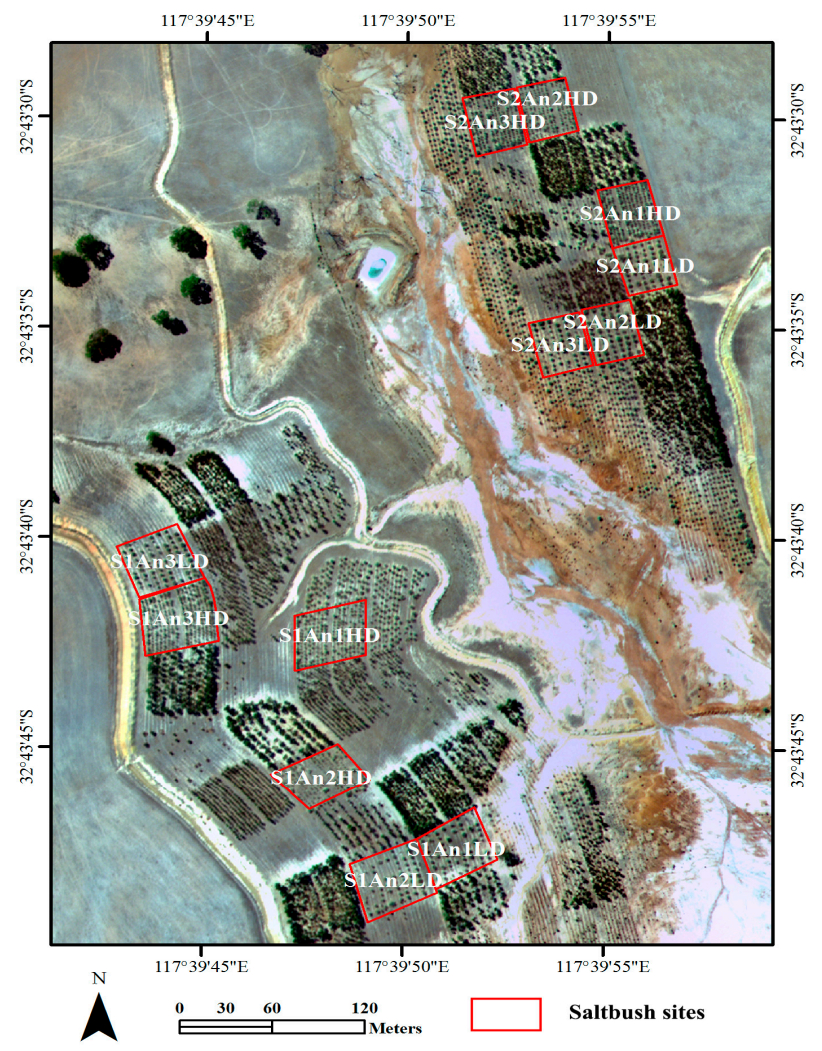

(a) S2An1LD

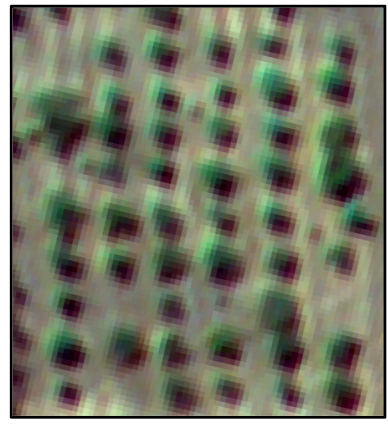

(b) S2An1HD

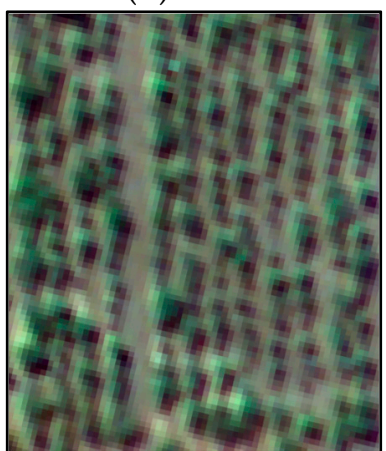

Figure 2. High spatial resolution airborne DMSI image $(0.5 \mathrm{~m})$ of the Wickepin experimental site taken on 24 March 2011 (dry season), with examples of: (a) low density (500 plants ha ${ }^{-1}$, plot S2An1LD); and (b) high density (2000 plants ha ${ }^{-1}$, plot S2An1HD). Plots were $40 \times 40 \mathrm{~m}^{2}$, with field imagery measurements taken from an internal $20 \times 20 \mathrm{~m}$ plot to minimize competitive edge effects. Key to plot name: S1, S2-Block; An—species (Atriplex nummularia); 1, 2, 3-Replicate; LD, HD—planting density (500 or 2000 plants ha ${ }^{-1}$ ).

\subsection{Ground Based Measurements}

Permanent measurement plots $(20 \times 20 \mathrm{~m})$ were established within the main treatment plots to minimise competitive edge effects. Measurement of potential predictor variables of A. nummularia shrubs were made of all plots which were applied to allometric relationships for estimates of carbon stocks in above- and belowground biomass.

Shrub crown width was measured on two axes at $90^{\circ}$ to each other and used to derive the mean crown diameter (MCD). Shrub height and crown base height were measured to determine the crown height and used to calculate a crown volume index (CVI) (1):

$$
\mathrm{CVI}=\left(\mathrm{Ht} \times \mathrm{W}_{1} \times \mathrm{W}_{2}\right) / 3
$$

where $\mathrm{Ht}$ is crown height, $\mathrm{W}_{1}$ is crown width along axis 1 , and $\mathrm{W}_{2}$ is crown width along axis 2 which is $90^{\circ}$ to axis 1 . All measurements are in meters.

Measurement of treatment plots was made on an annual basis following establishment [7] with the field measurements made on 10 December 2011, which was the closest sampling to the time of aerial digital data capture.

\subsection{Biomass Sampling}

The destructive harvest method described in Snowdon et al. [29] was used to estimate AGB and belowground biomass (BGB). A total of 54 A. nummularia shrubs were sampled for AGB, across the 
dynamic range of shrub sizes to ensure data were representative, and of these 22 were sampled for BGB.

Sampling the AGB involved the removal of the entire shrub above the soil surface. The shrubs were then weighed in the field to determine total fresh weight and subsamples $(0.5-0.7 \mathrm{~kg})$ were taken and dried at $70{ }^{\circ} \mathrm{C}$ to constant dry weight and the moisture content $(\% w / w)$ determined to calculate the dry above ground mass of the sampled shrubs. Subsamples were further separated into leaf and stem components to determine the proportion of these of the AGB.

Sampling the BGB was achieved by excavating with a backhoe to approximately $0.5 \mathrm{~m}$ and collecting all roots with a diameter of approximately $\geq 2 \mathrm{~mm}$. Soil was placed on a sieving table overlaid with $50 \mathrm{~mm}$ square mesh and roots were collected as described by Ritson and Sochacki [30]. The roots were washed to remove any adhering soil and then dried to determine the dry root weight.

There was no accumulation of soil organic carbon following A. nummularia establishment compared to untreated areas [11], thus it is not considered in this paper.

\subsection{Carbon Analysis}

Samples were taken from 8 random plants within the plots and analysed for carbon content. These were separated into leaf and stem components then dried at $70{ }^{\circ} \mathrm{C}$ to constant dry weight. The determination of carbon content of the leaves and stems was undertaken at a commercial laboratory, using the Leco combustion method [31].

\subsection{Allometric Relationships}

During Autumn, some A. nummularia leaves (L) are removed by livestock grazing, therefore the stable carbon store was considered to consist of the BGB and the stems of the AGB. Leaves represented $14.1 \%$ of the total plant biomass at the time of sampling [11]. The carbon store of each plant $\left(\mathrm{C}_{\mathrm{pl}}\right)$ was estimated in Equation (2):

$$
\mathrm{C}_{\mathrm{pl}}=\left(\mathrm{BGB} \times \mathrm{C}_{\mathrm{i}}\right)+\left((\mathrm{AGB}-\mathrm{L}) \times \mathrm{C}_{\mathrm{ii}}\right)
$$

where $\mathrm{C}$ is the carbon content of the $A$. nummularia plants; $\mathrm{BGB}$ is belowground biomass; AGB is aboveground biomass; and $\mathrm{L}$ is leaves. $\mathrm{C}_{\mathrm{i}}$ and $\mathrm{C}_{\mathrm{ii}}$ are the respective $\mathrm{C}$ compositional values of the roots $(46 \%)$ and stems (49\%) from Walden et al. [11].

Plant carbon $\left(\mathrm{C}_{\mathrm{pl}}\right)$ was then regressed against the CVI to develop a predictive allometric Equation (3):

$$
\mathrm{C}_{\mathrm{pl}}=0.494+4.607 \times \mathrm{CVI}
$$

where $\mathrm{C}_{\mathrm{pl}}$ was plant carbon and $\mathrm{CVI}$ is the crown volume index.

An estimate of total carbon stocks $\left(\mathrm{t} C \cdot \mathrm{ha}^{-1}\right)$ for each measurement plot was made by estimating the carbon content of each plant by applying Equation (3), summing these values for the measurement plot, and converting to a per hectare value:

$$
\mathrm{C}_{\mathrm{t}}=\sum \mathrm{C}_{\mathrm{pl}} \times 25
$$

where $C_{t}$ is the total carbon stocks $\left(t C \cdot h a^{-1}\right), C_{p l}$ is the carbon content of each plant and 25 is the value to convert from the $400 \mathrm{~m}^{2}$ measurement plot to $10,000 \mathrm{~m}^{2}$ (1 ha).

In this study, the ground measurements of carbon storage of saltbush conducted in December 2011 was the nearest observation to both remotely sensed images. At this site, minimal change in carbon storage in the saltbush planting was observed after 4 years of age [7].

\subsection{High Spatial Resolution Remote Sensing Data}

The DMSI sensor acquires 12-bit digital number (DN) data simultaneously in four narrow spectral bands ( $20 \mathrm{~nm}$ full width half maximum). The spectral bands are located in the visible and near-infrared (NIR) region of the electromagnetic spectrum using filters centred at $450 \mathrm{~nm}$ (blue), $550 \mathrm{~nm}$ (green), $675 \mathrm{~nm}$ (red), and $780 \mathrm{~nm}$ (NIR) [32]. 
Two high spatial resolution airborne DMSI images with $0.5 \mathrm{~m}$ pixels were acquired by SpecTerra Services Proprietary Limited (Perth, WA, Australia) [33] from an altitude of $2000 \mathrm{~m}$. The first DMSI image was acquired on the 28 September 2010 and is designated as the "September-2010-Green" image as this is when the saltbush shrubs are surrounded by green pastures containing photosynthetically active vegetation (PV). The second DMSI image was acquired on the 24 March 2011 and is designated as the "March-2011-Dry" image as this is when the saltbush shrubs are surrounded by dead/senesced pastures comprised predominantly of non-photosynthetically active vegetation (NPV).

The DMSI images were geo-referenced by SpecTerra based on GPS ground control points. Post-flight image processing included a bidirectional reflectance distribution function (BRDF) correction for variations in the sun-sensor-target viewing geometry across each image. The SpecTerra proprietary BRDF correction algorithm preserved the spectral integrity within an image, but produced $\mathrm{DN}$ rather than absolute radiance (energy received in $\mathrm{W} \mathrm{m}^{-2} \mathrm{sr}^{-1}$ ).

Further radiometric correction of these images was necessary to convert raw DN values to reflectance at ground, which is required for calculating vegetation indices. The atmospheric correction of the DMSI images to reflectance at the ground was made using a QUick Atmospheric Correction (QUAC) [34] applied though the ENVI 5.1 remote sensing package [35]. The QUAC atmospheric correction is applicable where no concurrent atmospheric measurements are available, and can be applied to either raw $\mathrm{DN}$ or radiance-at-sensor image values [34]. The resulting QUAC atmospherically corrected images were verified by extracting spectral profiles for "pure" pixels of a variety of materials identified through manual examination of each of the two images. The spectra from these "pure" pixel locations were also validated against laboratory spectra of vegetation, water and soil from the ASTER spectral library [36], to identify any gross differences despite the library materials not representing materials from the Australian environment.

\subsection{Vegetation Indices}

Five pixel-scale vegetation indices and the sub-pixel fractional green vegetation cover for individual plants were calculated from the high-resolution images in order to highlight the carbon content of saltbush in the high-resolution images. A classification-based index $R_{\mathrm{veg}}$, was also calculated for entire plots each image. These indices are summarized in Table 1.

Table 1. Vegetation indices used in this study.

\begin{tabular}{ccc}
\hline Vegetation Index & Formula & Reference \\
\hline Normalized Difference Vegetation Index & NDVI $=(\mathrm{NIR}-$ red $) /(\mathrm{NIR}+$ red $)$ & {$[37]$} \\
Ratio Vegetation Index & $\mathrm{RVI}=\mathrm{NIR} / \mathrm{red}$ & {$[38]$} \\
Soil Adjusted Vegetation Index & $\mathrm{SAVI}=1.5 \times(\mathrm{NIR}-\mathrm{red}) /(\mathrm{NIR}+\mathrm{red}+0.5)$ & {$[19,39]$} \\
Green Chromatic Coordinate & $\mathrm{GCC}=$ green $/(\mathrm{red}+$ green + blue $)$ & {$[40]$} \\
Fractional green vegetation cover & $\mathrm{fc}=(\mathrm{NDVI}-\mathrm{NDVI}$ soil $) /(\mathrm{NDVI}$ veg $-\mathrm{NDVI}$ soil $)$ & {$[41]$} \\
$\mathrm{R}_{\mathrm{veg}}$ & $\mathrm{R}_{\mathrm{veg}}=$ percentage of vegetation pixels for each plot & {$[25,42]$} \\
\hline
\end{tabular}

Note: NIR is the reflectance of the near-infrared band, red is the reflectance of the red band, green is the reflectance of the green band, and blue is the reflectance of the blue band. The radiometrically corrected DMSI images are used for vegetation index calculations.

The first group of vegetation indices used in this study was pixel-based. The NDVI is one of the most widely used vegetation indices as it provides a measure of absorption of red light by plant chlorophyll as well as the reflection of infrared radiation by water-filled cells $[37,43]$. The Soil Adjusted Vegetation Index (SAVI) has been found to be robust under variations in soil brightness. The SAVI was selected to reduce the impact of soil in the scene, as the extent of the canopy coverage of saltbush in our study area was relatively small due to the sparse spacing of the shrubs. The RVI was selected to capture the contrast between the red and infrared bands for vegetated pixels [17], and for its use of only two spectral bands. The green chromatic coordinate (GCC) was used in this study to test the performance of general optical bands for estimating saltbush biomass. GCC has been used as an indicator of plant 
condition and phenology $[18,40]$. The GCC was chosen as it can be readily calculated from spectral bands found in standard digital cameras, and so has the potential to be available from a variety of sensor platforms.

Two additional indices related to the spatial coverage of vegetation $\left(R_{\mathrm{veg}}\right.$ and fractional green vegetation cover $(\mathrm{fc})$ ) were used in this study. Crown horizontal projection, which refers to the vertical projected area of vegetation crown, has been reported as being strongly related to AGB [27], and canopy diameter is also strongly correlated to the AGB of saltbush in the study area [11], suggesting that the spatial coverage of vegetation can be an indicator of saltbush biomass. Calculating vegetation coverage can be complicated when the vegetation does not cover the entire pixel, resulting in mixed pixels on the edge of the saltbush canopy. In the study by Wittich and Hansing [41], the green vegetation fraction within a mixed pixel was shown to be related to the NDVI of the pixel, and also to the NDVI values of pure soil and vegetation in the scene. We therefore calculated fc by first selecting representative soil and vegetation samples manually from each image, and using NDVI to calculate fc for each pixel in the image according to the equation shown in Table $1 . R_{\mathrm{veg}}$ is a classification-based index that is calculated at the plot scale. $R_{\mathrm{veg}}$ is simply the proportion (\%) of vegetation pixels in a plot compared to the total number of pixels in that plot. The use of a classification index such as $R_{v e g}$ is appropriate for the sparse nature of the saltbush planting as it focuses just on pixels that have been classified as vegetation, while providing estimates of vegetation fraction at the plot scale. Unlike the $\mathrm{fc}_{\mathrm{c}}$ the $\mathrm{R}_{\mathrm{veg}}$ is dependent on the accuracy of the vegetation classification method.

\subsection{Object-Based Classification Method}

To determine the vegetation classifications for the calculation of $R_{v e g}$, we used an object-based classification method. Object-based classification is suitable for high-resolution images such as DMSI where the relationship between the pixel size and the typical canopy width means that the vegetation is resolved by multiple pixels. Instead of analyzing information in each pixel separately, the object-based classification method takes image objects with a set of similar pixels as the basic unit $[16,44]$. The aim of object-based classification is to delineate readily usable objects from the background pixels, in order to utilize spectral and contextual information in the image.

For this study, we chose to use the commercially available software eCognition $8.4[45,46]$ for object-based image classification as it contains a wide range of tools under a trial version. However, object-based image classification tools are available as both commercial and open-source products [16], which makes it possible to use these methods to develop an inexpensive operational system.

The object-based classification of our images to identify the salt-bush was made as follows. Each of the DMSI images was first segmented to identify individual objects in the scene using a "Bottom-Up" algorithm, "multi-resolution segmentation", in which all bands were used to split the original image into objects according to object shape, size, color, and pixel topology. The second stage of the object classification process is to assign each object identified by the segmentation process to a class based on features and criteria set by the user. We applied the "Assign class" and "Fuzzy membership" algorithms to the segmented objects from step 1, to identify "saltbush" within each image. As part of the input variables for the "Assign class" algorithm, an NDVI $>0.2$ was assigned as the "saltbush" class, while NDVI $<0.1$ was treated as "Soil" background. As saltbush is very sparse in some plots in the study area, a "Fuzzy membership" algorithm was used to classify "saltbush" and "soil" for NDVI between 0.1 and 0.2 . Visual examination of the resulting classification with the high-resolution base images was used to confirm the suitability of the final classification.

The difference in vegetation index values between the interspace pasture and saltbush in the dry season image (March-2011-Dry) was found to be more pronounced than in the green season image (September-2010-Green), as during this period the pasture had died whereas the saltbush (A. nummularia) was alive at all times (Figure 2). We therefore used only the dry season image for determining the vegetation classification, although the canopy crowns identified by the classification were applicable to both images. 


\subsection{Scale and Estimating Carbon Stocks in A. nummularia}

Two spatial scales, being the scales of the individual plant and of the whole plot, were used for relating the image data in this study to the carbon stocks of saltbush. "Plant scale" is where the relationship between vegetation indices and carbon stocks is determined only for the pixels in each plot that have been determined to be saltbush in the object-based classification. "Plot scale" is where all pixels within the plot, including vegetated and background pixels, are aggregated by averaging the values of all pixels within the plot.

\subsection{Statistical Analys}

All statistical analysis was made in the R 3.2.3 statistical software. A two-way analysis of variance (ANOVA) was conducted using the "anova" function in the "stats" package to detect the differences between vegetation type (Pasture and Saltbush) and the season of observation (Green and Dry) for all the image-derived vegetation indices.

The relationship between vegetation indices and carbon stocks was evaluated using a Spearman rank correlation in R 3.2.3 [47]. At the individual plant scale the non-saltbush plant pixels in each plot were treated as null values in all vegetation indices, while at the plot scale all pixels are included in the calculation.

Both non-linear relationships [21,48] and linear relationships [49-51] between vegetation indices and biomass were derived. The best-fit biomass estimation models were selected by comparing several regression models (exponential function, linear function, logarithm function, polynomial function, and power function). Each model was validated using the Leave-one-out cross validation (LOOCV) method. The precision of the estimation models was evaluated by the relative root mean squared error (RMSE, \%) and the coefficient of determination $\left(\mathrm{R}^{2}\right)$.

\section{Results}

\subsection{Vegetation Classification Based on Difference of Pasture and Saltbush}

The values of the vegetation indices for saltbush were generally significantly different from those for pasture $(p<0.001)$ in the vegetation indices for both the green season image (September-2010-Green) and the dry season image (March-2011-Dry). Moreover, the difference in the vegetation indices between saltbush and pasture was larger in the dry season than the green season. For example, the differences of NDVI and RVI were 0.17 and 0.65 in the dry season, and 0.13 and 0.48 in the green season, respectively (Table 2).

NDVI, RVI, SAVI, GCC, and fc all showed significant differences $(p<0.001)$ between pasture and saltbush, which are expected given the different absorption features of the red and NIR spectral bands used in these vegetation indices. The differences of SAVI, fc and GCC between saltbush and pasture in the dry season were $0.08,0.41$ and 0.02 , respectively.

Table 2. Comparison of vegetation indices and vegetation cover between pasture and saltbush from DMSI images for the green season (September-2010-Green) and dry season (March-2011-Dry).

\begin{tabular}{|c|c|c|c|c|c|c|}
\hline \multirow{2}{*}{ Variable } & & \multicolumn{2}{|c|}{ Green Season } & \multicolumn{2}{|c|}{ Dry Season } & \multirow{2}{*}{ ANOVA Two-Way } \\
\hline & & Pasture & Saltbush & Pasture & Saltbush & \\
\hline \multirow{4}{*}{ Vegetation Index } & NDVI & 0.13 & 0.26 & 0.11 & 0.28 & $* * *$ \\
\hline & RVI & 1.31 & 1.79 & 1.25 & 1.90 & $* * *$ \\
\hline & SAVI & 0.08 & 0.15 & 0.07 & 0.19 & $* * *$ \\
\hline & GCC & 0.35 & 0.37 & 0.32 & 0.34 & $* * *$ \\
\hline \multirow{2}{*}{ Vegetation coverage } & $\mathrm{fc}_{\mathrm{C}}$ & 0.14 & 0.60 & 0.13 & 0.54 & $* * *$ \\
\hline & $R_{\text {veg }}$ & 0.46 & 0.54 & 0.46 & 0.54 & - \\
\hline
\end{tabular}

Note: The radiometrically corrected DMSI images are used for these vegetation index calculations. ${ }^{* * *} p<0.001$ in a two-way ANOVA test for vegetation type group (Pasture and Saltbush) and seasonal group (green season and dry season). 
Figure 3 shows examples of the object-based vegetation classification. The main canopy of saltbush can be clearly recognized, with mean classification stability and best classification results from the eCognition analysis of 0.70 and 0.85 , respectively. In addition, RVI, fc, and NDVI also showed significant differences $(p<0.001)$ between pasture and saltbush, which mainly resulted from the different absorption features of red and NIR bands of vegetation. The differences in RVI, fc and NDVI between saltbush and pasture in the dry season were $0.19,0.26$ and 0.12 , respectively.
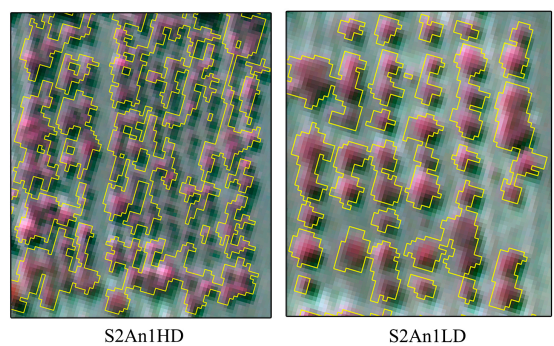

Figure 3. Examples of the object-based classification for the high density (S2An1HD) and low density plots (S2An1LD) of A. nummularia. The background images are false color composites, and the yellow boundaries are the derived canopy.

\subsection{Relationships between Digital Vegetation Indices and Carbon Stocks}

Overall, there was a significant relationship between all of the vegetation indices and carbon stocks (Tables 3 and 4, Figures 4, A1 and A2) in the dry season at both individual plant and plot scales, while a strong relationship was only observed at the individual plant scale in the green season. $\mathrm{R}_{\mathrm{veg}}$ was significantly related to carbon stocks ( $\varrho$ of $\left.0.91, p<0.001\right)$.
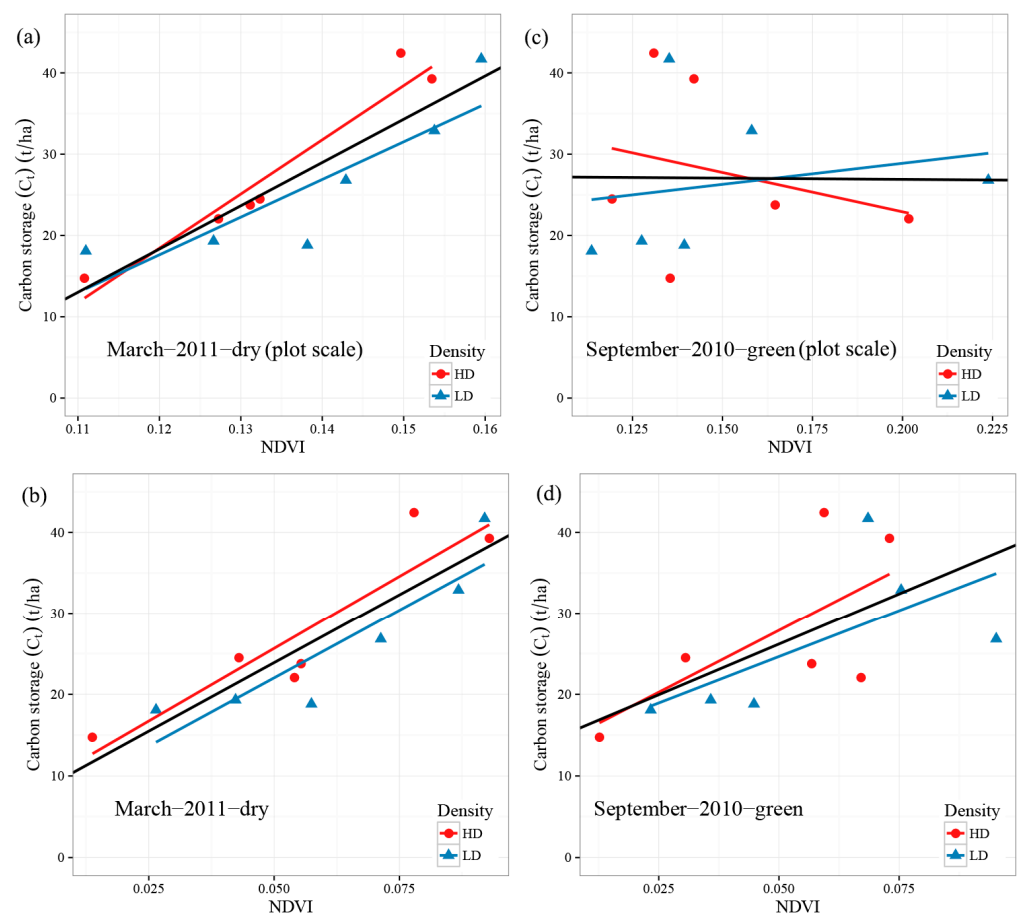

Figure 4. Relationship between vegetation indices and carbon stocks $\left(C_{t}\right)$ for the A. nummularia shrubs sampled from the $500\left(\Delta\right.$, LD symbols) and $2000\left(\bullet\right.$, HD symbols) plants ha ${ }^{-1}$ treatments in two seasons (dry season "March-2011-Dry" (a,b) and green season "September-2010-Green" (c,d)) at the plot scale $(\mathbf{a}, \mathbf{c})$ and the plant scale $(\mathbf{b}, \mathbf{d})$ of NDVI. The black line represents the fitted linear model for all plots and the red and blue lines are for high density and low density plots, respectively. 
Table 3. Spearman rank correlation tests of vegetation indices against carbon stocks $\left(\mathrm{C}_{\mathrm{t}}\right)$ in $A$. nummularia at the individual plant and whole plot scales in the green season (September-2010-Green).

\begin{tabular}{|c|c|c|c|c|c|}
\hline \multirow{3}{*}{ Variable } & & \multicolumn{4}{|c|}{ Scale } \\
\hline & & \multicolumn{2}{|c|}{ Individual Plant ${ }^{1}$} & \multicolumn{2}{|c|}{ Plot $^{2}$} \\
\hline & & $\varrho$ & $p$ & $\varrho$ & $p$ \\
\hline \multirow{4}{*}{ Vegetation Index } & NDVI & 0.73 & 0.01 & 0.16 & 0.62 \\
\hline & RVI & 0.80 & 0.003 & 0.23 & 0.47 \\
\hline & SAVI & 0.73 & 0.01 & 0.04 & 0.92 \\
\hline & GCC & 0.89 & 0.001 & 0.14 & 0.67 \\
\hline Vegetation coverage & $\mathrm{fc}$ & 0.55 & 0.05 & 0.16 & 0.62 \\
\hline
\end{tabular}

Table 4. Spearman rank correlation tests of vegetation indices against carbon stocks $\left(\mathrm{C}_{\mathrm{t}}\right)$ in $A$. nummularia at the individual plant and whole plot scales in the dry season (March-2011-Dry).

\begin{tabular}{lccccc}
\hline & & \multicolumn{3}{c}{ Scale } \\
\cline { 3 - 6 } Variable & & \multicolumn{2}{c}{ Individual Plant $^{\mathbf{1}}$} & \multicolumn{3}{c}{ Plot $^{2}$} \\
\cline { 3 - 6 } & & $\varrho$ & $p$ & $\varrho$ & $p$ \\
\hline \multirow{2}{*}{ Vegetation Index } & NDVI & 0.86 & 0.001 & 0.88 & 0.001 \\
& RVI & 0.895 & 0.0002 & 0.88 & 0.001 \\
& SAVI & 0.895 & 0.001 & 0.85 & 0.001 \\
& GCC & 0.91 & 0.0001 & 0.42 & 0.18 \\
\hline \multirow{2}{*}{ Vegetation coverage } & fc & 0.87 & 0.001 & 0.88 & 0.001 \\
& $\mathrm{R}_{\text {veg }}$ & 0.91 & 0.0001 & - & - \\
\hline
\end{tabular}

\footnotetext{
1 Pasture pixels were omitted for each plot (only pixels of saltbush canopies were combined for analysis); 2 The indices were the averaged values of the whole plot. $\varrho$ is Spearman's correlation coefficient and $p$ is the significance of the Spearman test.
}

At the individual plant scale, RVI and GCC were strongly correlated to carbon storage ( $\varrho$ of $0.9, p<0.001)$ in both seasons. The fc showed a much higher correlation in the dry season ( $\varrho$ of 0.87 , $p<0.001)$ than in the green season $(\varrho$ of $0.55, p<0.05)$. The relationship between NDVI and carbon and between SAVI and carbon were not as strong in different seasons ( $\varrho$ of 0.7 in September-2010-Green and $\varrho$ of 0.9 in March-2011-Dry).

In contrast, the results at the plot scale were more varied in both seasons. Very weak relationships between vegetation indices and carbon stocks were found in the green season, while a strong relationship, except for GCC, were found in the dry season. Similar strong relationships between NDVI, RVI, SAVI and fc with carbon storage were apparent in the dry season ( $\varrho$ of $0.88, p<0.001$ ). However, GCC showed a very weak relationship with carbon in both seasons.

For the data around different plot densities, a similar correlation was observed between vegetation indices and carbon stocks in the dry season, while in the green season significant relationships were only found for GCC and RVI at the individual plant scale (Figure 4). Meanwhile, there was no significant difference between slopes of linear regression lines derived from low and high density plots.

For space limitations, Figure 4 represents the model types of NDVI. All of the fitted model types for each vegetation index are available in Appendix Materials (Table A2 and Figures A1 and A2).

\subsection{Comparison of Carbon Estimation Methods for Different Seasons and Scales}

In the green season, all vegetation indices performed weakly in estimating carbon storage of saltbush at the plot scale (Figure A1). At the individual plant scale, RVI produced a reasonable result, explaining around $70 \%(p<0.05)$ of the variation in carbon storage (Figure A2). GCC was found to be 
the best index for estimating carbon in the green season (Figure A2), with an $\mathrm{R}^{2}$ of 0.86 and RMSE of $12.9 \%$. In the dry season, similar results were found at the individual plant scale and the plot scale for each vegetation index except for GCC. GCC was one of the best indicators for carbon estimation at the individual plant scale, with an $\mathrm{R}^{2}$ of 0.89 (RMSE $=12.4 \%$ and LOOCV RMSE $=15.8 \%$ ) and $p<0.01$, but it was not suitable at the plot scale $\left(\mathrm{R}^{2}=0.1, p>0.1\right)$. NDVI, RVI and fc all showed similarly good results, explaining around $80 \%(p<0.01$ and RMSE $<16 \%)$ of the variation when all plots were included and $85 \%$ of the variation $(p<0.01$, RMSE $<13 \%)$ in individual plant scale.

Overall, the relationships for the dry season and at the individual plant scale showed the best results for estimating saltbush biomass from the vegetation indices (Figure A2, Tables 3 and 4). By comparing the measures ( $\mathrm{R}^{2}$, RMSE, and LOOCV RMSE) of each regression model (Table A2), the best-fit regression model for carbon estimation was demonstrated in Table 5. Overall, very similar regressions and correlation coefficients were found from these vegetation indices. When all plots are included, the exponential function model showed almost the same precision as the polynomial function model for all vegetation indices. However, there were differences in the strength of the relationship with planting density. For the lower density plots, the polynomial function model was the best-fit model, explaining $96 \%$ of the variation $(p<0.01$, RMSE $<7 \%$ ), whereas for the higher density plot, the exponential function model showed a bit better performance than the polynomial function model, which explained $90 \%(p<0.01$, RMSE $<12 \%)$ of the variation.

In comparison with $f_{c}$, the relationship between $R_{v e g}$ and $C_{t}$ was stronger, explaining $88 \%$ $(p<0.001)$ of the variation when all plots were considered with a best-fit polynomial function model (Figure 5). Similar to vegetation indices, there were differences in the strength of this relationship with planting density, with the model for the high density plots explaining $87 \%$ of the variation $(p<0.01$, RMSE $=12.9 \%)$, whereas that for the lower density plot explained $96 \%$ of the variation $(p<0.01$, RMSE $=6.7 \%$ ) when the polynomial function model was used for carbon estimation.

Table 5. Models for estimating carbon stocks $\left(\mathrm{C}_{\mathrm{t}}\right)$ of $A$. nummularia for different planting densities at the individual plant scale in the dry season (March-2010-dry). Model is the best-fit regression model, $\mathrm{R}^{2}$ is the coefficient of determination, RMSE is the relative root mean square error (\%) of carbon estimation.

\begin{tabular}{|c|c|c|c|c|c|}
\hline \multirow{2}{*}{ Variable } & & \multirow{2}{*}{ Model } & \multirow{2}{*}{$\mathbf{R}^{2}$} & RMSE & \multirow{2}{*}{$\begin{array}{c}\text { Density } \\
\left.\text { (Plants ha }^{-1}\right)\end{array}$} \\
\hline & & & & $(\%)$ & \\
\hline \multirow[t]{12}{*}{ Vegetation index } & NDVI & $y=12.29 e^{13.44 x}$ & 0.89 & 11.9 & 2000 \\
\hline & & $y=7916.3 x^{2}-618.11 x+29.584$ & 0.96 & 6.5 & 500 \\
\hline & & $y=12.06 e^{12.62 x}$ & 0.84 & 14.6 & ALL \\
\hline & RVI & $\mathrm{y}=12.10 \mathrm{e}^{1.79 \mathrm{x}}$ & 0.9 & 11.9 & 2000 \\
\hline & & $y=155.96 x^{2}-89.983 x+30.676$ & 0.96 & 6.2 & 500 \\
\hline & & $\mathrm{y}=11.61 \mathrm{e}^{1.78 \mathrm{x}}$ & 0.87 & 12.9 & ALL \\
\hline & SAVI & $\mathrm{y}=12.10 \mathrm{e}^{21.09 x}$ & 0.88 & 11.7 & 2000 \\
\hline & & $y=18485 x^{2}-891.27 x+28.446$ & 0.92 & 9.6 & 500 \\
\hline & & $y=11.89 e^{20.04 x}$ & 0.84 & 15 & ALL \\
\hline & GCC & $y=11.97 e^{7.96 x}$ & 0.89 & 12 & 2000 \\
\hline & & $y=3573.8 x^{2}-457.16 x+32.411$ & 0.96 & 6.2 & 500 \\
\hline & & $y=11.28 e^{8.29 x}$ & 0.89 & 12 & ALL \\
\hline \multirow[t]{6}{*}{ Vegetation coverage } & $\mathrm{fc}$ & $y=12.43 e^{7.83 x}$ & 0.89 & 12 & 2000 \\
\hline & & $y=2525 x^{2}-341.96 x+28.97$ & 0.96 & 6.7 & 500 \\
\hline & & $y=12.42 e^{7.05 x}$ & 0.81 & 15.8 & ALL \\
\hline & $R_{\text {veg }}$ & $y=11.97 e^{2.72 x}$ & 0.89 & 12 & 2000 \\
\hline & & $y=398.08 x^{2}-148.79 x+31.764$ & 0.96 & 6.5 & 500 \\
\hline & & $y=178.87 x^{2}-22.86 x+16.40$ & 0.89 & 11.9 & ALL \\
\hline
\end{tabular}



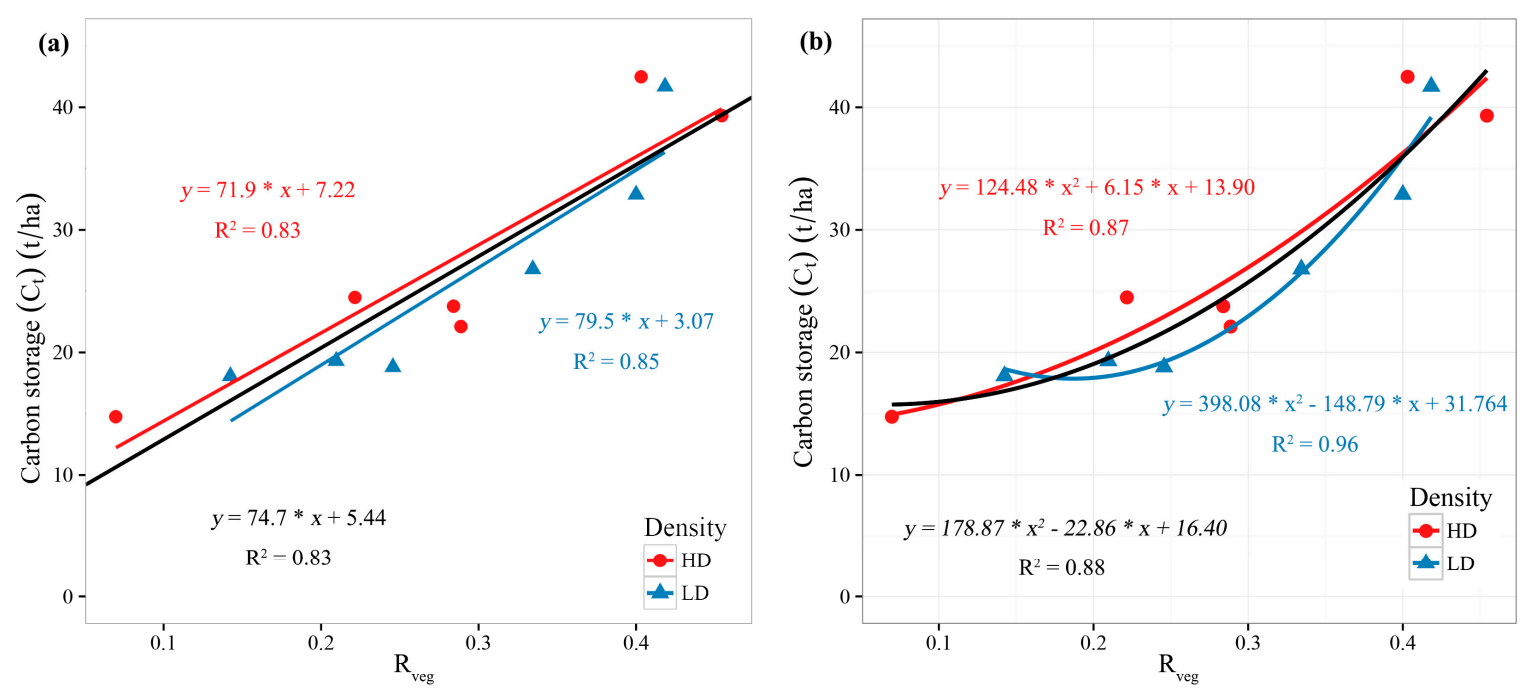

Figure 5. The relationship between the ratio of vegetation pixels $\left(R_{v e g}\right)$ and carbon stocks $\left(C_{t}\right)$ for the A. nummularia shrubs sampled from the $500\left(\Delta, \mathrm{LD}\right.$ symbols) and $2000\left(\bullet, \mathrm{HD}\right.$ symbols) plants ha ${ }^{-1}$ treatments with: linear (a) and non-linear (b) regression models fitted.

\section{Discussion}

\subsection{Characteristics and Dynamics of Vegetation Indices of Saltbush and Annual Pasture}

Overall, saltbush showed higher canopy coverage and higher biomass than pasture in both seasons, and the spectral signatures and the derived vegetation indices allowed discrimination between the two vegetation types from the images. These differences were particularly marked in the red band, with differences of the red band between pasture and saltbush of $29.5 \%$ in the green season and $34.4 \%$ in the dry season. It is thus possible to successfully distinguish pasture and saltbush canopy with an object-based classification method. Due to the senescence of pasture in the dry season, the physical, visual, and spectral differences between saltbush and pasture were much more pronounced in the images than in the green season, thus the dry season is the best time in this Mediterranean climate for vegetation classification. This difference has implications for future design of vegetation monitoring using image data.

Although nearly $90 \%$ of the planted saltbush had survived during the study time frame, the values of fc were moderate in both the green season (0.60) and dry season (0.54), which indicates that a greater proportion of the plots were covered by pasture and bare soil than by saltbush. This was confirmed by visual examination of the images. The low vegetation coverage and high salinity (EM38 $\mathrm{H}$ ranging from 50 to $300 \mathrm{mS} \mathrm{m}^{-1}$ ) [7] at the field sites resulted in generally low values of the NIR-based vegetation indices in the study area [52]. For example, the mean NDVI of saltbush was 0.28 in the dry season and 0.26 in the green season, while the mean RVI was 1.9 and 1.8 in the same period.

\subsection{Indicators of Carbon Stocks $\left(C_{t}\right)$}

It can be concluded from the Spearman's rank correlation test of vegetation indices against sequestered carbon (C) that vegetation indices calculated from red and NIR bands can accurately reflect the carbon storage for saltbush both at the individual plant and plot scale (Tables 3 and 4 ) in the dry season (March-2011-Dry image). However, in the green season (September-2010-Green image), carbon storage could only be suitably estimated at the individual plant scale, as the pasture in the green season was still alive (NDVI values of around 0.13 ), which dramatically changed the estimated total carbon storage for each plot. Meanwhile, only GCC and RVI showed reasonable results for estimating carbon of saltbush in the green season, again indicating that the best time for estimating saltbush biomass with remote sensing data is in the dry season. 
GCC was significantly related to carbon storage of saltbush at the individual plant scale in both the dry and green seasons, which suggests that indices derived from bands only in the visible part of the electromagnetic spectrum, and without including a NIR band, can be a useful indicator of saltbush biomass. GCC has also been found to be a good indicator of vegetation health and phenology in other studies [18,40], as GCC best represented differences in healthy vigour and mortality of vegetation. Meanwhile, from the different relationship of GCC between plot and individual plot scales, it can be concluded that the best performance of GCC requires vegetation classification, suggesting that model precision is determined by the accuracy of vegetation classification. In addition, there was only a small difference between the Pasture and Saltbush values of GCC, with these showing a considerable contribution to model performance at plot scale.

Vegetation coverage indices ( $f c$ and $R_{v e g}$ ) were strongly correlated to $C_{t}$ at both the individual plant and plot scale, suggesting that canopy coverage of saltbush inherently reflects carbon storage. In addition, $R_{v e g}$ in this study area produced a better result than $f_{c}$. The calculation of fc required the NDVI values of pure soil and vegetation, which is a source of additional uncertainty in the index. In this study, mean NDVI values from pure soil and vegetation samples within the image were used for calculating $\mathrm{fc}$. However, there is still a high variation on both vegetation structure and soil properties. In order to increase the accuracy of fc, a spatial interpolation method could be used to predict variations in the spectral characteristics of bare soil and green vegetation across space.

The results for the $\mathrm{R}_{\mathrm{veg}}$ are consistent with that of Suganuma et al. [25] who used remote sensing derived canopy coverage to estimate stand biomass in forest species (Acacia aneura and Eucalyptus camaldulensis) in arid Western Australia. Similarly, Sousa et al. [27], working on Quercus rotundifolia in southern Portugal, found that AGB as a function of crown horizontal projection had the same trend for individual trees and plots, even though estimation for individual trees produced large individual errors. For our study, the strong relationship between vegetation coverage and $C_{t}$ can possibly be explained by $A$. nummularia having little variation in height due to the consistency in age and the strong relationship between diameter and biomass reported by Walden et al. [11]. This is in contrast to many forest inventory studies where there is canopy closure and, thus, it is not possible to differentiate between individual trees and height has a large contribution to overall tree mass. For both this study and that of Suganuma et al. [25], the canopies were separated, thus we can suggest that canopy coverage approaches may be applicable to carbon inventory in open woodlands as well as shrubby systems. Similar relationships between canopy coverage and biomass have also been reported in the semiarid savanna of Sudan [53], and in semi-arid Senegal [54]. However, different vegetation types showed significantly different estimation accuracy [26].

For other vegetation indices in our study (i.e., NDVI, SAVI and RVI) that are derived from red and NIR bands, similar strong relationships with carbon storage of saltbush were observed at both individual plant and plot scales. This similarity may be because of their use of the same spectral bands (Table 1). Both NDVI and RVI have been widely used for estimating AGB $[17,23,43,55,56]$.

Linear regression has been widely used to build the relationship between vegetation indices and carbon stocks, which demonstrates a satisfactory performance for carbon estimation. Overall, the linear regression models indicated strong relationships between the vegetation indices and carbon stocks, explaining around $80 \%$ of the variation, while the exponential function models explained around $85 \%$ of the variation (Table A2). However, in this study, the exponential function and polynomial function models showed much better accuracy than the linear model in the comparison with different densities (Figure 5). Similarly, other studies found close relationships between RVI and AGB with power and exponential functions [57]. A power function model was also found for grassland [21,48]. Furthermore, Santin-Janin et al. [58] developed a generalized non-linear model for the relationship between biomass and NDVI for Acaena magellanica and Taraxacum officinale. Meanwhile, as for the sensitivity of vegetation indices to planting density, a slightly stronger relationship was found in low density plots $\left(\mathrm{R}^{2}=0.96, p \sim 0.01\right)$ than in high density plots $\left(\mathrm{R}^{2} \sim 0.90, p \sim 0.01\right)$ at the individual plant scale (Figures 5 and A2), but at the plot scale, a much higher difference occurred (Figure A1). 
This difference between the low and high density plots can be ascribed to the effects of a higher ratio of pasture in the low density plots than in high density plots. In addition to the effects of Pasture at plot scale, the accuracy of vegetation classification can be another factor inducing a different relationship between low and high density plots. The difference of the best-fit regression model between high and low density plots also resulted from the different canopy coverage of each plant. Generally, low density plots have a higher canopy coverage (an average of $2.66 \times 2.80 \mathrm{~m}^{2}$ ) than those in high density plots (an average of $1.51 \times 1.56 \mathrm{~m}^{2}$ ) [7], which resulted in the different performance of each vegetation index on carbon estimation. Besides, carbon storage can be different even for the same canopy coverage because of the difference in height of plants between low (an average of $2.1 \mathrm{~m}$ ) and high density (an average of $1.7 \mathrm{~m})$ plots.

\subsection{Limitations and Future Research}

The object-based classification method was successfully used to distinguish pasture and saltbush from the high resolution image data. Although the efficacy of the technique was demonstrated here at a single location, the underlying allometric equation between saltbush carbon yield and stand parameters had been calibrated at six sites across southern Australia [11], and this suggests that our results are broadly applicable across other regions.

The mean classification stability and best classification results were 0.7 and 0.85 , respectively, but there is still uncertainty related to the identification of the boundary of each saltbush plant. Although the annual pastures had died/senesced by the time the dry season image was acquired, it was still difficult to distinguish the boundary of each saltbush due to its overall low coverage (approximate fc of 0.17 to 0.69 ). Moreover, compared to the size of the saltbush canopy (an average of $\left.1.79 \times 1.85 \mathrm{~m}^{2}\right)$, the pixel size of our image $(0.5 \mathrm{~m})$ is still relatively coarse, which makes the pixels in the boundary area to be a mixture of both soil background and saltbush branches, especially in high density plots. Therefore, it is impossible to find a fixed threshold to distinguish saltbush and soil. The spectral response from saltbush in some pixels may be confounded by that from the soil background, and saltbush pixels could therefore be misclassified as pasture during the classification process. Therefore, the potential use of images with finer pixels should enhance the accuracy of remotely sensed data in the future.

The relationships between remote sensing indices and carbon storage will vary in relation to the site-specific properties of soil condition, shadow, different species, and canopy structure. Meanwhile, soil background also has high spatial and seasonal variation. Therefore, the regression quality reported by previous studies varies strongly, $\mathrm{R}^{2}$ with a range of 0.32 to 0.95 and our relationships may only be suitable for similar climatic and vegetation types as in the study, especially as the assumption of a set root mass to canopy relationship is inherent in our calibration data. However, our findings do demonstrate the capability of this approach to estimate carbon stocks using high-resolution remote sensing images in vegetation with non-overlapping canopies.

The applicability of our results could be further validated in other regions where abandoned farmland is being revegetated to ameliorate negative impacts of agricultural practices. With the advent of unmanned aerial vehicle (UAV) technology, there is the potential to gain significantly higher resolution imagery at a much lower cost (ca. USD $\$ 4000$ for a DJI Phantom 4 Pro and a NDVI supported camera [59]) and with far greater flexibility of application and hence the rapid and cheap assessment of carbon. Recent examples of sensors mounted on UAV have included pixel resolutions as fine as $0.01 \mathrm{~m}$, which provides sufficiently detailed information for estimating biomass of crops and monitoring forests [60]. The technical specifications of sensors mounted on UAV clearly have the potential to be used for monitoring biomass of vegetation used for carbon stocks, but the design of such a monitoring system has additional requirements, such as determining the best seasonal timing of measurements and assessing the potential for monitoring at the tree- or stand-scale.

With the possibility of finer resolution images for monitoring vegetation, remote sensing methodologies could potentially deliver estimates of biomass with greater precision and accuracy, 
as more accurate classification results are likely to be achieved for canopy classification with the Objective-based classification method. Finally, as canopy coverage and vegetation indices show high accuracy for estimating carbon stocks at the plot scale, some frequently used sources of image data, for example, Landsat-TM and SPOT, which are of medium spatial resolution and can provide an estimation of canopy coverage, may also be useful for broad scale biomass estimation.

\section{Conclusions}

This study suggests that there is a potential to use high spatial resolution airborne digital multispectral imagery to rapidly estimate the carbon storage of shrublands resulting from revegetation of abandoned farmland. Carbon stocks were significantly correlated with both canopy coverage and spectrally-based vegetation indices with or without the use of the NIR band. With the comparison of seasonal performances on carbon estimation, we concluded that estimates of saltbush carbon storage could be enhanced by image acquisition during the dry season even without the refinement of using a vegetation classification in the image analysis. This approach will have application in the management of revegetation-based carbon sink projects generally, and particularly in situations where this revegetation is based on discrete shrubs or trees in open woodlands. This is applicable not only to the large areas of land affected by salinity in Australia but also to similar degraded lands in other countries and particularly where these lands form part of the respective countries national carbon mitigation targets (INDCs). Historic aerial photography exists in many areas and the strength of our relationships based on canopy coverage and GCC implies that this photography could be interpreted to produce estimates of long-term carbon dynamics. To extend the present study, further ground-truthing is required to test these models on other Atriplex stands in other regions where aboveground biomass estimations are already known.

Acknowledgments: We thank SpecTerra Services Proprietary Limited and Dustin Bridges in particular for their substantial support in providing the ortho-rectified DMSI images utilized for this study. The Martin family is thanked for continuous access to their farm and the experimental site, and John Carter is thanked for comments on the manuscript. Ning Liu is supported by the Chinese Academy of Forestry and a Murdoch University Strategy PhD Scholarship. This study is funded by the Special Research Program for Public-welfare Forestry (Grant No. 201404201).

Author Contributions: Ning Liu, Richard Harper, Bradley Evans, Rebecca N. Handcock and Bernard Dell conceived and designed the experiments; Ning Liu, Richard Harper and Rebecca N. Handcock wrote the paper; Ning Liu analyzed the data; Stanley Sochacki and Lewis Walden contributed data and allometric equations and edited the paper; and Shirong Liu edited the paper.

Conflicts of Interest: The authors declare no conflict of interest.

\section{Appendix A}

Table A1 Mean values for vegetation indices and sequestered $\mathrm{CO}_{2}$ results per plot in 2010 and 2011. Table A2 Models for estimating carbon stocks $\left(C_{t}\right)$ of $A$. nummularia for different planting densities at the individual plant scale in the dry season (March-2010-dry). Figure A1. Relationship between vegetation indices and carbon stocks $\left(C_{t}\right)$ for the $A$. nummularia shrubs sampled from the 500 and 2000 plants ha ${ }^{-1}$ treatments in two seasons (dry season "March-2011-Dry" and green season "September-2010-Green") at plot scale. Figure A2. Relationship between vegetation indices and carbon stocks $\left(C_{t}\right)$ for the $A$. nummularia shrubs sampled from the 500 and 2000 plants ha ${ }^{-1}$ treatments in two seasons (dry season "March-2011-Dry" and green season "September-2010-Green") at individual plant scale. 
Table A1. Mean values for vegetation indices and sequestered $\mathrm{CO}_{2}$ results per plot in 2010 and 2011.

\begin{tabular}{|c|c|c|c|c|c|c|c|}
\hline Plot Name & Year & NDVI & RVI & SAVI & GCC & fc & Carbon Stocks $\left(\mathrm{C}, \mathrm{t} \cdot \mathrm{ha}^{-1}\right)$ \\
\hline \multirow[b]{2}{*}{ S1An1LD } & 2010 & 0.17 & 1.42 & 0.10 & 0.37 & 0.29 & \multirow[b]{2}{*}{19.3} \\
\hline & 2011 & 0.20 & 1.52 & 0.13 & 0.35 & 0.35 & \\
\hline \multirow{2}{*}{ S1An2LD } & 2010 & 0.16 & 1.40 & 0.09 & 0.37 & 0.26 & \multirow{2}{*}{18.1} \\
\hline & 2011 & 0.19 & 1.47 & 0.12 & 0.34 & 0.31 & \\
\hline \multirow{2}{*}{ S1An3LD } & 2010 & 0.29 & 1.82 & 0.15 & 0.39 & 0.69 & \multirow{2}{*}{26.8} \\
\hline & 2011 & 0.21 & 1.56 & 0.14 & 0.34 & 0.37 & \\
\hline \multirow{2}{*}{ S2An1LD } & 2010 & 0.19 & 1.47 & 0.11 & 0.37 & 0.35 & \multirow{2}{*}{32.9} \\
\hline & 2011 & 0.22 & 1.57 & 0.14 & 0.34 & 0.38 & \\
\hline \multirow{2}{*}{ S2An2LD } & 2010 & 0.16 & 1.40 & 0.09 & 0.37 & 0.26 & \multirow{2}{*}{41.7} \\
\hline & 2011 & 0.22 & 1.59 & 0.14 & 0.34 & 0.39 & \\
\hline \multirow{2}{*}{ S2An3LD } & 2010 & 0.18 & 1.46 & 0.10 & 0.37 & 0.33 & \multirow{2}{*}{18.8} \\
\hline & 2011 & 0.23 & 1.64 & 0.14 & 0.34 & 0.42 & \\
\hline \multirow{2}{*}{ S1An1HD } & 2010 & 0.20 & 1.51 & 0.12 & 0.38 & 0.39 & \multirow{2}{*}{23.8} \\
\hline & 2011 & 0.20 & 1.49 & 0.13 & 0.34 & 0.33 & \\
\hline \multirow{2}{*}{ S1An2HD } & 2010 & 0.18 & 1.45 & 0.11 & 0.38 & 0.33 & \multirow{2}{*}{14.7} \\
\hline & 2011 & 0.20 & 1.51 & 0.13 & 0.35 & 0.34 & \\
\hline \multirow{2}{*}{ S1An3HD } & 2010 & 0.23 & 1.62 & 0.12 & 0.38 & 0.50 & \multirow{2}{*}{22.1} \\
\hline & 2011 & 0.19 & 1.47 & 0.12 & 0.34 & 0.31 & \\
\hline \multirow[b]{2}{*}{ S2An1HD } & 2010 & 0.15 & 1.35 & 0.08 & 0.36 & 0.20 & \multirow[b]{2}{*}{42.5} \\
\hline & 2011 & 0.19 & 1.49 & 0.12 & 0.34 & 0.33 & \\
\hline \multirow{2}{*}{ S2An2HD } & 2010 & 0.14 & 1.32 & 0.08 & 0.37 & 0.17 & \multirow{2}{*}{24.5} \\
\hline & 2011 & 0.19 & 1.49 & 0.13 & 0.34 & 0.33 & \\
\hline \multirow{2}{*}{ S2An3HD } & 2010 & 0.16 & 1.39 & 0.09 & 0.37 & 0.25 & \multirow{2}{*}{39.3} \\
\hline & 2011 & 0.20 & 1.53 & 0.13 & 0.34 & 0.35 & \\
\hline
\end{tabular}

Table A2. Models for estimating carbon stocks $\left(\mathrm{C}_{\mathrm{t}}\right)$ of A. nummularia for different planting densities at the individual plant scale in the dry season (March-2010-dry). Model is the fitted regression models (exponential function model, linear function model, logarithm function model, polynomial function model, and power function model), $\mathrm{R}^{2}$ is the coefficient of determination, RMSE is the relative root mean square error (\%) of estimate, and LOOCV RMSE is the RMSE from leave-one-out cross-validation (LOOCV).

\begin{tabular}{|c|c|c|c|c|c|}
\hline Variable & & Model & $\mathbf{R}^{2}$ & RMSE (\%) & LOOCV RMSE (\%) \\
\hline \multirow[t]{20}{*}{ Vegetation index } & \multirow[t]{5}{*}{ NDVI } & $y=12.06 e^{12.62 x}$ & 0.84 & 14.6 & 16.8 \\
\hline & & $y=335.87 x+7.09$ & 0.78 & 16.1 & 18.8 \\
\hline & & $y=13.68 \ln (x)+67.28$ & 0.63 & 20.9 & 27.8 \\
\hline & & $y=3290.91 x^{2}-36.87 x+15.64$ & 0.83 & 14.4 & 17.5 \\
\hline & & $y=122.52 x^{0.53}$ & 0.75 & 17.2 & 20.4 \\
\hline & \multirow[t]{5}{*}{ RVI } & $y=11.61 e^{1.78 x}$ & 0.87 & 12.9 & 15.3 \\
\hline & & $y=47.28 x+6.09$ & 0.81 & 14.9 & 17.9 \\
\hline & & $y=14.23 \ln (x)+40.22$ & 0.64 & 20.5 & 28.6 \\
\hline & & $y=70.47 x^{2}-11.85 x+16.24$ & 0.87 & 12.5 & 15.9 \\
\hline & & $y=42.68 x^{0.56}$ & 0.78 & 16.1 & 19.3 \\
\hline & \multirow[t]{5}{*}{ SAVI } & $y=11.89 e^{20.04 x}$ & 0.84 & 15 & 17.6 \\
\hline & & $y=530.30 x+6.83$ & 0.77 & 16.3 & 19.2 \\
\hline & & $y=13.95 \ln (x)+74.20$ & 0.63 & 20.9 & 27.7 \\
\hline & & $\mathrm{y}=7923.11 \mathrm{x}^{2}-41.81 \mathrm{x}+15.24$ & 0.81 & 14.8 & 18.1 \\
\hline & & $y=161.53 x^{0.55}$ & 0.74 & 17.4 & 20.7 \\
\hline & \multirow[t]{5}{*}{ GCC } & $y=11.28 e^{8.29 x}$ & 0.89 & 12 & 15 \\
\hline & & $y=220.24 x+5.35$ & 0.83 & 14.4 & 17.5 \\
\hline & & $y=14.72 \ln (x)+62.73$ & 0.65 & 20.3 & 29.3 \\
\hline & & $y=1520.43 x^{2}-62.34 x+16.19$ & 0.89 & 11.5 & 15.8 \\
\hline & & $\mathrm{y}=102.84 \mathrm{x}^{0.57}$ & 0.80 & 15.4 & 18.6 \\
\hline
\end{tabular}


Table A2. Cont.

\begin{tabular}{cccccc}
\hline Variable & & Model & $\mathbf{R}^{\mathbf{2}}$ & RMSE (\%) & LOOCV RMSE (\%) \\
\hline Vegetation coverage & fc & $\mathrm{y}=12.42 \mathrm{e}^{7.05 \mathrm{x}}$ & 0.81 & 14.9 & 18 \\
& & $\mathrm{y}=187.72 \mathrm{x}+7.86$ & 0.76 & 16.9 & 19.5 \\
& & $\mathrm{y}=13.28 \ln (\mathrm{x})+58.98$ & 0.62 & 21.2 & 27.3 \\
& $\mathrm{y}=945.73 \mathrm{x}^{2}+2.22 \mathrm{x}+15.18$ & 0.79 & 15.7 & 18.9 \\
& $\mathrm{y}=88.60 \mathrm{x}^{0.52}$ & 0.72 & 18 & 21.2 \\
& $\mathrm{y}=11.32 \mathrm{e}^{2.81 \mathrm{x}}$ & 0.89 & 11.9 & 14.6 \\
& \multirow{2}{*}{$\mathrm{R}_{\mathrm{veg}}$} & $\mathrm{y}=74.71 \mathrm{x}+5.44$ & 0.83 & 14.3 & 17.4 \\
& & $\mathrm{y}=14.62 \ln (\mathrm{x})+46.75$ & 0.65 & 20.3 & 29.5 \\
& & $\mathrm{y}=178.87 \mathrm{x}^{2}-22.86 \mathrm{x}+16.40$ & 0.89 & 11.4 & 15.4 \\
& & $\mathrm{y}=55.11 \mathrm{x}^{0.57}$ & 0.80 & 15.4 & 18.6 \\
\hline
\end{tabular}
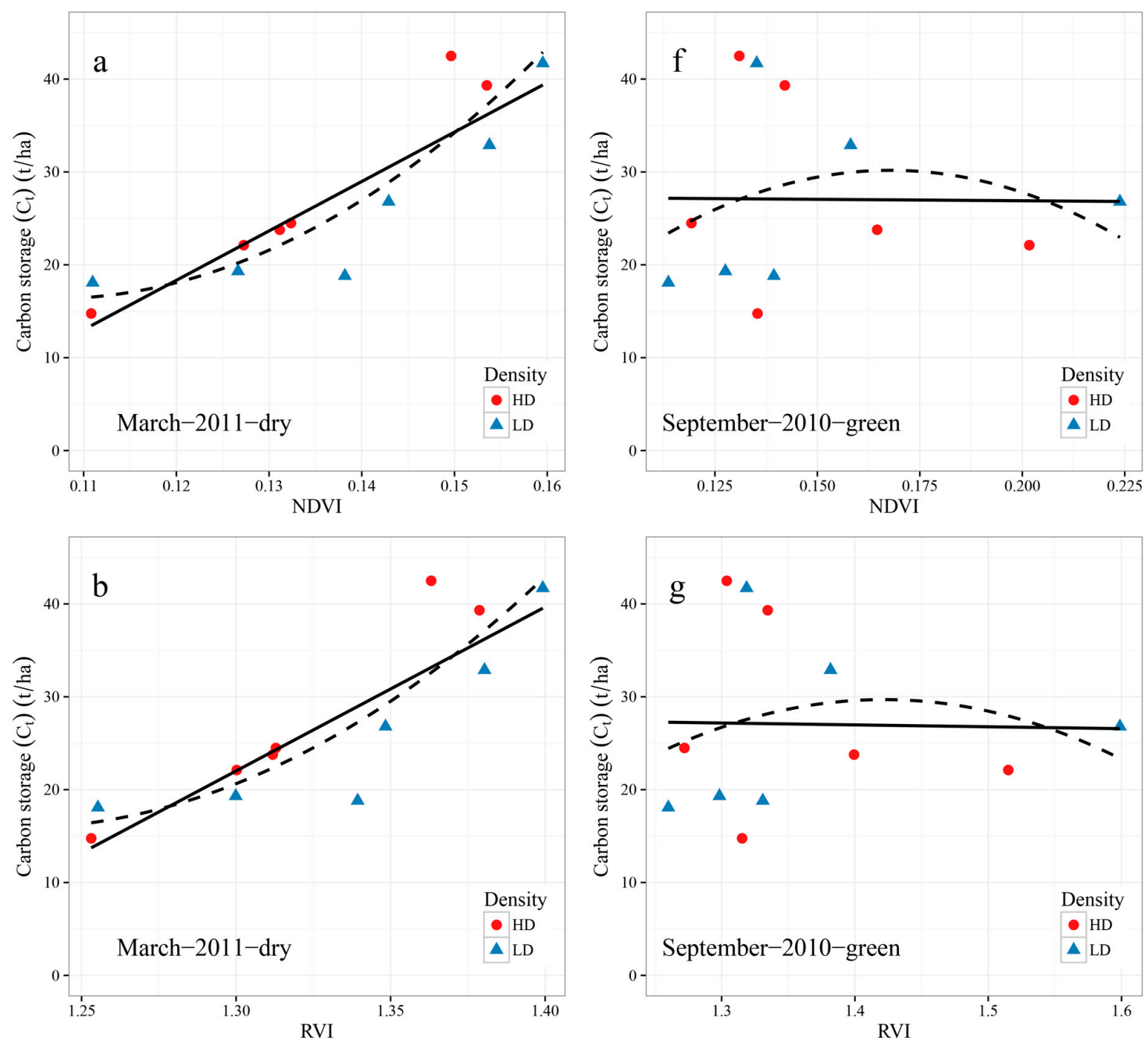

Figure A1. Cont. 

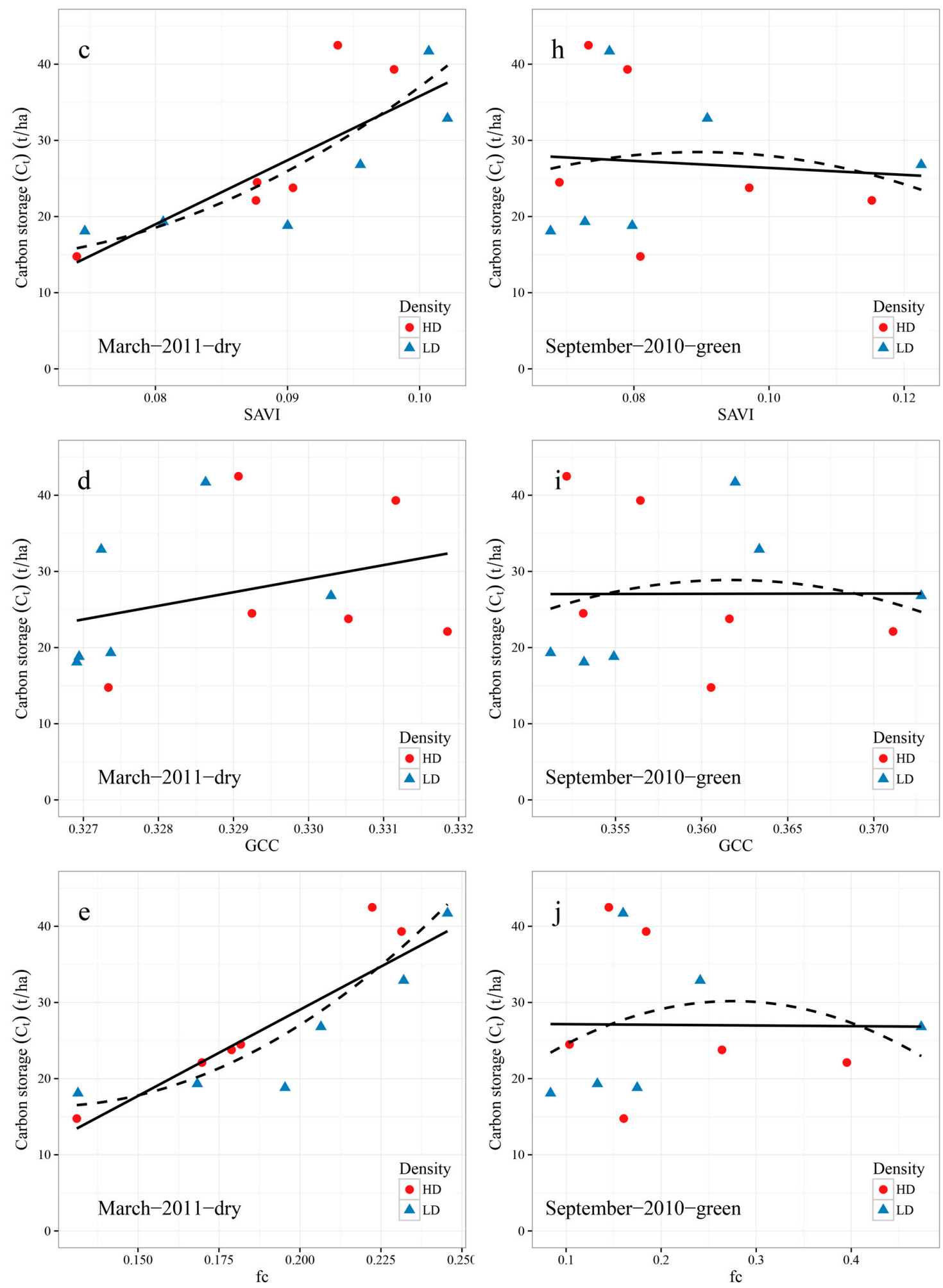

Figure A1. Relationship between vegetation indices and carbon stocks $\left(\mathrm{C}_{\mathrm{t}}\right)$ for the $A$. nummularia shrubs sampled from the 500 ( $\triangle$, LD symbols) and 2000 (•, HD symbols) plants ha ${ }^{-1}$ treatments in two seasons (dry season "March-2011-Dry" (a-e) and green season "September-2010-Green" (f-j)) at plot scale. The straight line is the linear model and dashed line is the non-linear regression model fitted. 

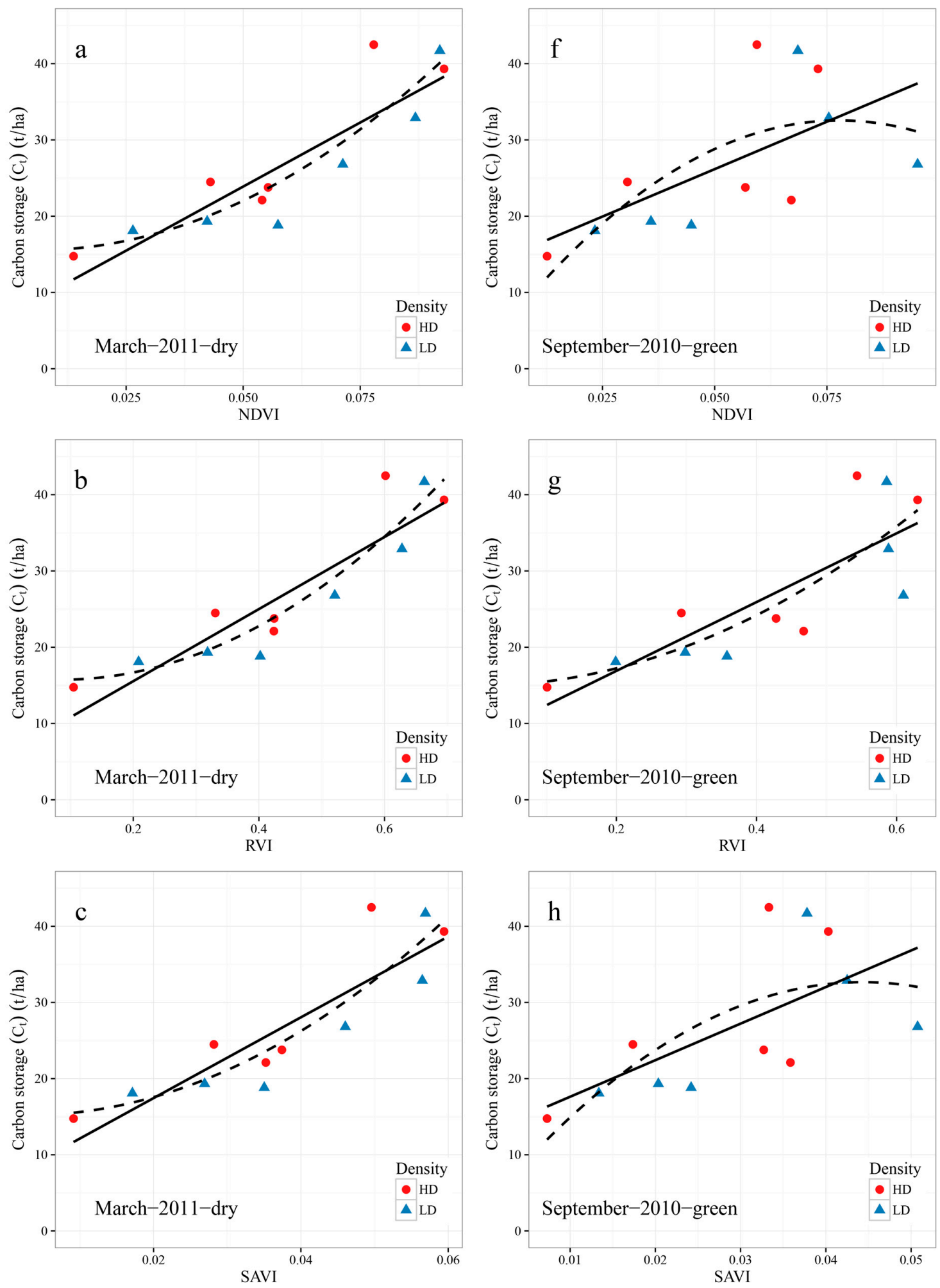

Figure A2. Cont. 

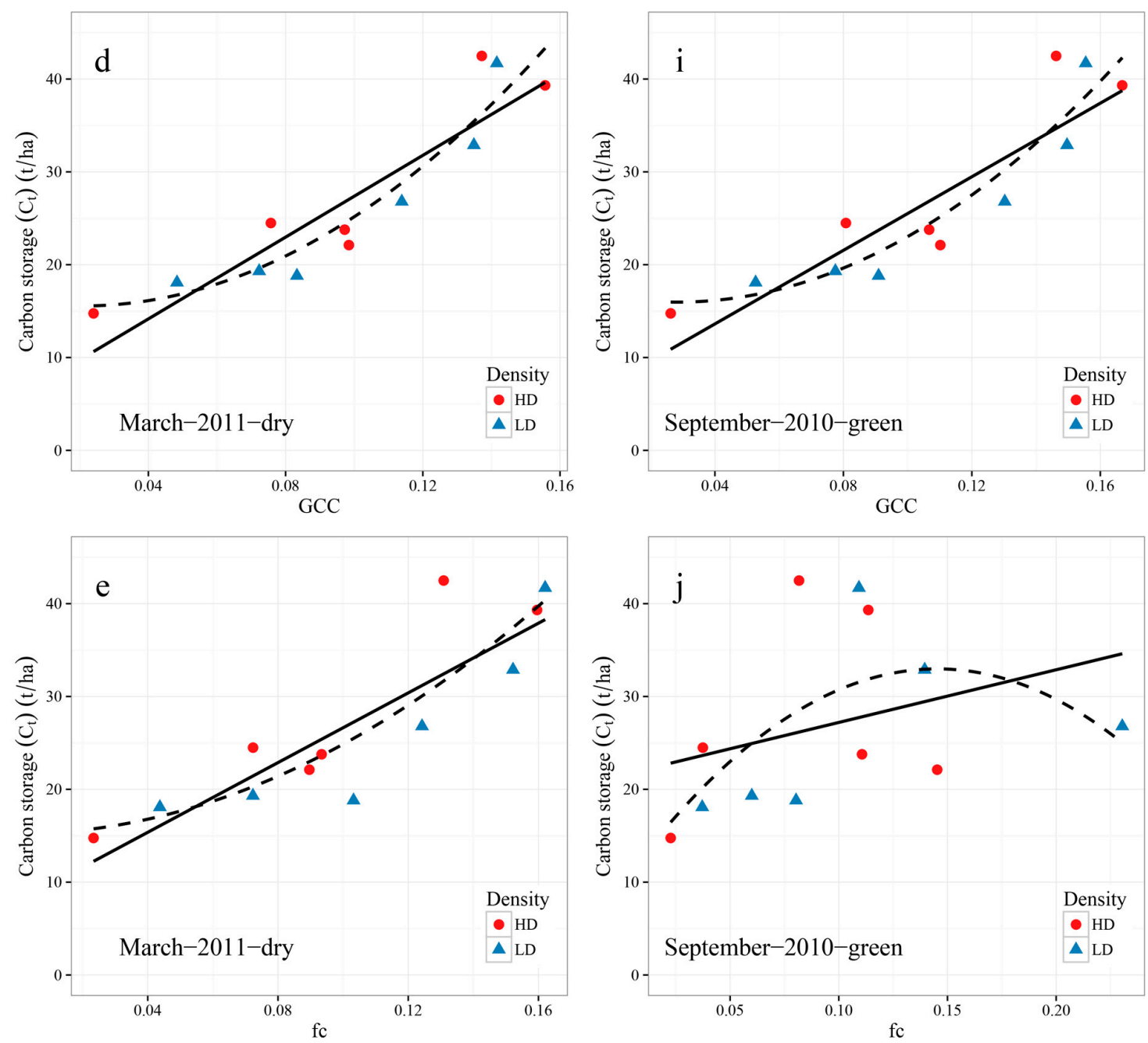

Figure A2. Relationship between vegetation indices and carbon stocks $\left(\mathrm{C}_{\mathrm{t}}\right)$ for the A. nummularia shrubs sampled from the $500\left(\Delta, \mathrm{LD}\right.$ symbols) and $2000\left(\bullet, \mathrm{HD}\right.$ symbols) plants $\mathrm{ha}^{-1}$ treatments in two seasons (dry season "March-2011-Dry" (a-e) and green season “September-2010-Green" (f-j)) at individual plant scale. The straight line is the linear model and dashed line is the non-linear regression model fitted.

\section{References}

1. Intergovernmental Panel on Climate Change (IPCC). IPCC, 2013: Climate Change 2013: The Physical Science Basis. Contribution of Working Group I to the Fifth Assessment Report of the Intergovernmental Panel on Climate Change; Cambridge University Press: Cambridge, UK; New York, NY, USA, 2013; p. 1535.

2. Bustamante, M.; Robledo-Abad, C.; Harper, R.; Mbow, C.; Ravindranat, N.H.; Sperling, F.; Haberl, H.; Pinto Ade, S.; Smith, P. Co-benefits, trade-offs, barriers and policies for greenhouse gas mitigation in the agriculture, forestry and other land use (afolu) sector. Glob. Chang. Biol. 2014, 20, 3270-3290. [CrossRef] [PubMed]

3. Harper, R.J.; Beck, A.C.; Ritson, P.; Hill, M.J.; Mitchell, C.D.; Barrett, D.J.; Smettem, K.R.J.; Mann, S.S. The potential of greenhouse sinks to underwrite improved land management. Ecol. Eng. 2007, 29, 329-341. [CrossRef]

4. Food and Agriculture Organization (FAO). The Agriculture Sectors in the Intended Nationally Determined Contributions: Summary; Food and Agriculture Organization of the United Nations: Rome, Italy, 2016; pp. 3-4. 
5. Smith, P.; Haberl, H.; Popp, A.; Erb, K.H.; Lauk, C.; Harper, R.J.; Tubiello, F.; de Siqueira Pinto, A.; Jafari, M.; Sohi, S.; et al. How much land based greenhouse gas mitigation can be achieved without compromising food security and environmental goals? Glob. Chang. Biol. 2013, 19, 2285-2302. [CrossRef] [PubMed]

6. Jackson, R.B.; Jobbagy, E.G.; Avissar, R.; Roy, S.B.; Barrett, D.J.; Cook, C.W.; Farley, K.A.; le Maitre, D.C.; McCarl, B.A.; Murray, B.C. Trading water for carbon with biological carbon sequestration. Science 2005, 310, 1944-1947. [CrossRef] [PubMed]

7. Sochacki, S.J.; Harper, R.J.; Smettem, K.R.J. Bio-mitigation of carbon following afforestation of abandoned salinized farmland. GCB Bioenergy 2012, 4, 193-201. [CrossRef]

8. Australian Bureau of Statistics. 1370.0-Measures of Australia's Progress. 2010. Available online: http:// www.abs.gov.au/ausstats/abs@.nsf/Lookup/by\%20Subject/1370.0 2010 Chapter Salinity\%20(6.2.4.4) (accessed on 3 March 2010).

9. National Land and Water Resources Audit. Australian Dryland Salinity Assessment 2000. Extent, Impacts, Processes, Monitoring and Management Options; National Land and Water Resources Audit: Canberra, Australia, 2001; p. 129.

10. Food and Agriculture Organization (FAO). More Information on Salt-Affected Soils. Available online: http:/ / www.fao.org/soils-portal/soil-management/management-of-some-problem-soils/salt-affectedsoils/more-information-on-salt-affected-soils/en/ (accessed on 15 February 2017).

11. Walden, L.L.; Harper, R.J.; Sochacki, S.J.; Montagu, K.D.; Wocheslander, R.; Clarke, M.; Ritson, P.; Emms, J.; Davoren, C.W.; Mowat, D.; et al. Mitigation of carbon following Atriplex nummularia revegetation in southern Australia. Ecol. Eng. 2017, in review.

12. Harper, R.J.; Sochacki, S.J.; Smettem, K.R.J.; Robinson, N. Bioenergy feedstock potential from short-rotation woody crops in a dryland environment. Energy Fuels 2010, 24, 225-231. [CrossRef]

13. Macintosh, A. The carbon farming initiative: Removing the obstacles to its success. Carbon Manag. 2013, 4, 185-202. [CrossRef]

14. Phinn, S.; Roelfsema, C.; Dekker, A.; Brando, V.; Anstee, J. Mapping seagrass species, cover and biomass in shallow waters: An assessment of satellite multi-spectral and airborne hyper-spectral imaging systems in moreton bay (Australia). Remote Sens. Environ. 2008, 112, 3413-3425. [CrossRef]

15. Blaschke, T. Object based image analysis for remote sensing. ISPRS J. Photogramm. Remote Sens. 2010, 65, 2-16. [CrossRef]

16. Bunting, P.; Lucas, R. The delineation of tree crowns in australian mixed species forests using hyperspectral Compact Airborne Spectrographic Imager (CASI) data. Remote Sens. Environ. 2006, 101, 230-248. [CrossRef]

17. Silleos, N.G.; Alexandridis, T.K.; Gitas, I.Z.; Perakis, K. Vegetation indices: Advances made in biomass estimation and vegetation monitoring in the last 30 years. Geocarto Int. 2006, 21, 21-28. [CrossRef]

18. Reid, A.M.; Chapman, W.K.; Prescott, C.E.; Nijland, W. Using excess greenness and green chromatic coordinate colour indices from aerial images to assess lodgepole pine vigour, mortality and disease occurrence. For. Ecol. Manag. 2016, 374, 146-153. [CrossRef]

19. Huete, A.; Didan, K.; Miura, T.; Rodriguez, E.P.; Gao, X.; Ferreira, L.G. Overview of the radiometric and biophysical performance of the modis vegetation indices. Remote Sens. Environ. 2002, 83, 195-213. [CrossRef]

20. Ogaya, R.; Barbeta, A.; Başnou, C.; Peñuelas, J. Satellite data as indicators of tree biomass growth and forest dieback in a mediterranean holm oak forest. Ann. For. Sci. 2014, 72, 135-144. [CrossRef]

21. Jin, Y.X.; Yang, X.C.; Qiu, J.J.; Li, J.Y.; Gao, T.; Wu, Q.; Zhao, F.; Ma, H.L.; Yu, H.D.; Xu, B. Remote sensing-based biomass estimation and its spatio-temporal variations in temperate grassland, northern china. Remote Sens. 2014, 6, 1496-1513. [CrossRef]

22. Zheng, D.L.; Rademacher, J.; Chen, J.Q.; Crow, T.; Bresee, M.; le Moine, J.; Ryu, S.R. Estimating aboveground biomass using landsat $7 \mathrm{ETM}+$ data across a managed landscape in northern wisconsin, USA. Remote Sens. Environ. 2004, 93, 402-411. [CrossRef]

23. Helman, D.; Mussery, A.; Lensky, I.M.; Leu, S. Detecting changes in biomass productivity in a different land management regimes in drylands using satellite-derived vegetation index. Soil Use Manag. 2014, 30, 32-39. [CrossRef]

24. Asner, G.P. Biophysical and biochemical sources of variability in canopy reflectance. Remote Sens. Environ. 1998, 64, 234-253. [CrossRef] 
25. Suganuma, H.; Abe, Y.; Taniguchi, M.; Tanouchi, H.; Utsugi, H.; Kojima, T.; Yamada, K. Stand biomass estimation method by canopy coverage for application to remote sensing in an arid area of western australia. For. Ecol. Manag. 2006, 222, 75-87. [CrossRef]

26. Fensham, R.J.; Fairfax, R.J.; Holman, J.E.; Whitehead, P.J. Quantitative assessment of vegetation structural attributes from aerial photography. Int. J. Remote Sens. 2002, 23, 2293-2317. [CrossRef]

27. Sousa, A.M.O.; Goncalves, A.C.; Mesquita, P.; da Silva, J.R.M. Biomass estimation with high resolution satellite images: A case study of quercus rotundifolia. ISPRS J. Photogramm. Remote Sens. 2015, 101, 69-79. [CrossRef]

28. Harper, R.J.; Sochacki, S.J.; Smettem, K.R.J.; Robinson, N.; Silberstein, R.P.; Clarke, C.J.; McGrath, J.F.; Crombie, D.S.; Hampton, C.E. Catchment Scale Evaluation of "Trees, Water and Salt"; Rural Industries Research and Development Corporation: Kingston, Australia, 2009.

29. Snowdon, P.; Keith, H.; Raison, R.J. Protocol for Sampling Tree and Stand Biomass; Australian Greenhouse Office Parkes: Canberra, Australia, 2002.

30. Ritson, P.; Sochacki, S. Measurement and prediction of biomass and carbon content of Pinus pinaster trees in farm forestry plantations, south-western Australia. For. Ecol. Manag. 2003, 175, 103-117. [CrossRef]

31. Rayment, G.; Higginson, F.R. Australian Laboratory Handbook of Soil and Water Chemical Methods; Inkata Press Pty Ltd.: Melbourne, Australia, 1992.

32. Evans, B.; Lyons, T.; Barber, P.; Stone, C.; Hardy, G. Enhancing a eucalypt crown condition indicator driven by high spatial and spectral resolution remote sensing imagery. J. Appl. Remote Sens. 2012, 6, 3605. [CrossRef]

33. SpecTerra Services Pty Ltd.-Global Leaders in Airborne Remote Sensing Technology. Available online: http:/ / www.specterra.com.au (accessed on 29 May 2017).

34. Bernstein, L.S.; Jin, X.; Gregor, B.; Adler-Golden, S.M. Quick atmospheric correction code: Algorithm description and recent upgrades. Opt. Eng. 2012, 51, 111719. [CrossRef]

35. ENVI Image Analysis Software I ESRI Australia. Available online: https://esriaustralia.com.au/productsspecialised-gis-applications-envi (accessed on 29 May 2017).

36. Baldridge, A.M.; Hook, S.J.; Grove, C.I.; Rivera, G. The aster spectral library version 2.0. Remote Sens. Environ. 2009, 113, 711-715. [CrossRef]

37. Tucker, C.J. Red and photographic infrared linear combinations for monitoring vegetation. Remote Sens. Environ. 1979, 8, 127-150. [CrossRef]

38. Birth, G.S.; McVey, G. Measuring the color of growing turf with a reflectance spectroradiometer. Agron. J. 1968, 60, 640-643. [CrossRef]

39. Huete, A.R. A soil-adjusted vegetation index (SAVI). Remote Sens. Environ. 1988, 25, 295-309. [CrossRef]

40. Nijland, W.; de Jong, R.; de Jong, S.M.; Wulder, M.A.; Bater, C.W.; Coops, N.C. Monitoring plant condition and phenology using infrared sensitive consumer grade digital cameras. Agric. For. Meteorol. 2014, 184, 98-106. [CrossRef]

41. Wittich, K.-P.; Hansing, O. Area-averaged vegetative cover fraction estimated from satellite data. Int. J. Biometeorol. 1995, 38, 209-215. [CrossRef]

42. Karlson, M.; Ostwald, M.; Reese, H.; Sanou, J.; Tankoano, B.; Mattsson, E. Mapping tree canopy cover and aboveground biomass in sudano-sahelian woodlands using landsat 8 and random forest. Remote Sens. 2015, 7, 10017-10041. [CrossRef]

43. Ahamed, T.; Tian, L.; Zhang, Y.; Ting, K.C. A review of remote sensing methods for biomass feedstock production. Biomass Bioenergy 2011, 35, 2455-2469. [CrossRef]

44. Yu, Q.; Gong, P.; Clinton, N.; Biging, G.; Kelly, M.; Schirokauer, D. Object-based detailed vegetation classification with airborne high spatial resolution remote sensing imagery. Photogramm. Eng. Remote Sens. 2006, 72, 799-811. [CrossRef]

45. Ding, X.Y. The application of ecognition in land use projects. Geomat. Spat. Inf. Technol. 2005, 28, 116-120.

46. eCognition I Trimble. Available online: http:/ / www.ecognition.com (accessed on 29 May 2017).

47. Van de Wiel, M.; Di Bucchianico, A. Fast computation of the exact null distribution of spearman's $\varrho$ and page's 1 statistic for samples with and without ties. J. Stat. Plan. Inference 2001, 92, 133-145. [CrossRef]

48. Frank, A.B.; Karn, J.F. Vegetation indices, $\mathrm{CO}_{2}$ flux, and biomass for northern plains grasslands. J. Rangel. Manag. 2003, 56, 382-387. [CrossRef] 
49. Perry, E.M.; Morse-McNabb, E.M.; Nuttall, J.G.; O'Leary, G.J.; Clark, R. Managing wheat from space: Linking modis ndvi and crop models for predicting australian dryland wheat biomass. IEEE J. STARS 2014, 7, 3724-3731. [CrossRef]

50. Yan, F.; Wu, B.; Wang, Y.J. Estimating spatiotemporal patterns of aboveground biomass using Landsat TM and MODIS images in the Mu US Sandy Land, China. Agric. For. Meteorol. 2015, 200, 119-128. [CrossRef]

51. Ediriweera, S.; Pathirana, S.; Danaher, T.; Nichols, D. Estimating above-ground biomass by fusion of lidar and multispectral data in subtropical woody plant communities in topographically complex terrain in north-eastern australia. J. For. Res. 2014, 25, 761-771. [CrossRef]

52. Peñuelas, J.; Isla, R.; Filella, I.; Araus, J.L. Visible and near-infrared reflectance assessment of salinity effects on barley. Crop Sci. 1997, 37, 198-202. [CrossRef]

53. Olsson, K. Estimating canopy cover in drylands with landsat mss data. Adv. Space Res. 1984, 4, 161-164. [CrossRef]

54. Woomer, P.L.; Touré, A.; Sall, M. Carbon stocks in senegal's sahel transition zone. J. Arid Environ. 2004, 59, 499-510. [CrossRef]

55. Roy, P.S.; Ravan, S.A. Biomass estimation using satellite remote sensing data-An investigation on possible approaches for natural forest. J. Biosci. 1996, 21, 535-561. [CrossRef]

56. Richardson, A.J.; Everitt, J.H.; Gausman, H.W. Radiometric estimation of biomass and nitrogen-content of Alicia grass. Remote Sens. Environ. 1983, 13, 179-184. [CrossRef]

57. Kaishan, S.; Bai, Z.; Fang, L.; Hongtao, D.; Zongming, W. Correlative analyses of hyperspectral reflectance, soybean lai and aboveground biomass. Trans. Chin. Soc. Agric. Eng. 2005, 1, 9.

58. Santin-Janin, H.; Garel, M.; Chapuis, J.L.; Pontier, D. Assessing the performance of NDVI as a proxy for plant biomass using non-linear models: A case study on the Kerguelen archipelago. Polar Biol. 2009, 32, 861-871. [CrossRef]

59. Sentera-Drones + Software to Make Sense of It All. Available online: https://sentera.com/ (accessed on 29 May 2017).

60. Zahawi, R.A.; Dandois, J.P.; Holl, K.D.; Nadwodny, D.; Reid, J.L.; Ellis, E.C. Using lightweight unmanned aerial vehicles to monitor tropical forest recovery. Biol. Conserv. 2015, 186, 287-295. [CrossRef]

(C) 2017 by the authors. Licensee MDPI, Basel, Switzerland. This article is an open access article distributed under the terms and conditions of the Creative Commons Attribution (CC BY) license (http:/ / creativecommons.org/licenses/by/4.0/). 